UNITED STATES DEPARTMENT OF THE INTERIOR GEOLOGICAL SURVEY

\title{
USGS FM Cassette Selsmlc-Refraction Recording System
}

\author{
J. M. Murphyl
}

\begin{abstract}
DISCLAIMER
This report was prepared as an account of work sponsored by an agency of the United States Government. Neither the United States Government nor any agency thereof, nor any of their employees, makes any warranty, express or implied, or assumes any legal liability or responsibility for the accuracy, completeness, or usefulnes" of any information, apparatus, product, or process disclosed, or represents that its use would not infringe privately owned rights. Reference herein to any specific commercial product, process, or 'ervice by trade name, trademark, manufacturer, or otherwise does not necessarily constitu! or imply its endorsement, recommendation, or favoring by the United States Government or any agency thereof. The views and opinions of authors expressed herein do not necessarily state or reflect those of the United States Government or any agency thereof.
\end{abstract}

Open-F1le Report $88-570$

This report is preliminary and has not been reviewed for conformity with U.S. Geological Survey editorial standards. Any use of trade, product or firm names is for descriptive purposes only and does not 1mply endorsement by the U.S. Government.

1. USGS, Menlo Park, Cal1fornia

1988

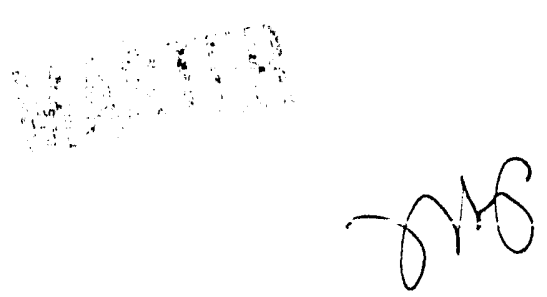


TABLE OF CONTENTS

Page

Chapter 1 Seismic-Refraction Data Acquisition System

1.0 Introduction ................................... 2

1.1 Recording UnIt................................... 7

1.2 Digitizing Unit................................. 10

1.3 System Response.................................. 12

1.4 Dlagnost1cs and Calibration......................... 18

1.5 Time Code...................................... 20

Chapter 1 FIgures

1.1 Schematic diagram of the data aquisition

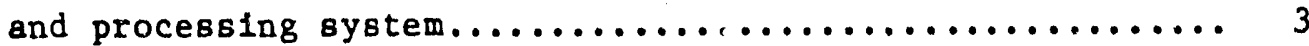

1.2 Plcture of the Recording Unit........................4

1.3 Schemat1c diagrain of the recording sequence............ 5

1.4 Picture of the Dig1t1zing Un1t...................... 6

1.5 Block dlagram of the recording un1t c1rcult board8........ 8

1.6 Block diagram of the amplifler/vCO board................99

1.7 Block diagram of the digitizing un1t................. 11

1.8 Time code parallel transmission word format............. 13

1.9 Amplitude-response curve......................... 17

1.10 Diagnost1c and calibration sequence.................. 19

1.11 IRIG-E tIme code.............................. 21

Chapter 1 Tables

1.1 Component parameters of the recording

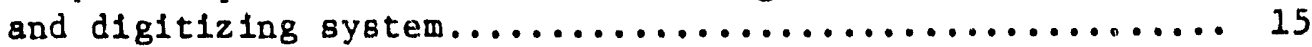

1.2 Aluplitude response values for the major components

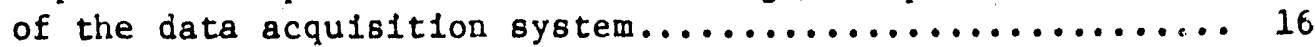

1.3 Gain values for selected attenuation settings........... 16

1.4 Manufacturers of the major components................. 22

Chapter 2 Selsmic Cassette Recorder Users Gulde

2.1 Intruduction.................................... 24

2.2 Defintions and general information.................... 24

2.2 .1 Recording parameters........................ 24

2.2 .2 Battertes................................. 29

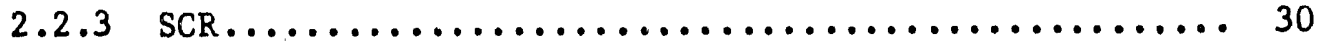

2.2 .4 Fleld notes............................. 30

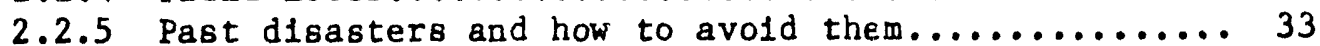

2.3 Description of HHT and SCR controls.................. 33

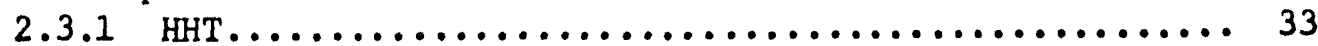

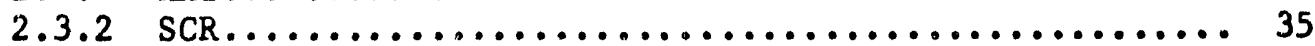


2.4 Programming procedures before deployment............. 38

2.4.1 Programming the HHT....................... 38

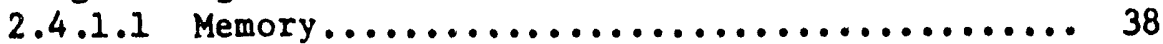

2.4.1.2 Synchronizing the Internal clock.......... 38

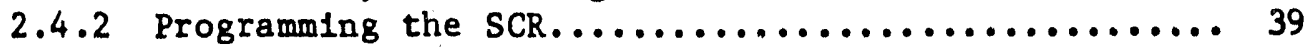

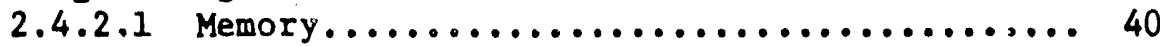

2.4.2.2 Synchronlzing the Internal clock......... 40

2.4.2.3 Attenuations and cassette tape.......... 40

2.4.3 Charging the SCR batteries.................... 41

2.5 Procedure after retrieval of the SCRs................. 41

2.5.1 Recording drift times...................... 41

2.6 Miscellaneous HHT features...................... 41

Chapter 2 Flgures

2.1 Schematic diagram of the recording sequence............ 25

2.2 Schemat1c dlagram of the extended recording sequence....... 28

2.3 Schematic diagram of the resistor barik................ 29

2.4 Selsmic cassette recorder (SCR).................... 30

2.5 Recorder fleld data sheet........................ 31

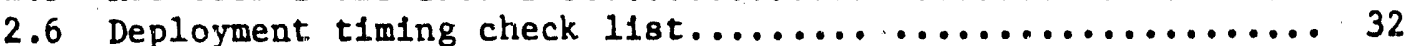

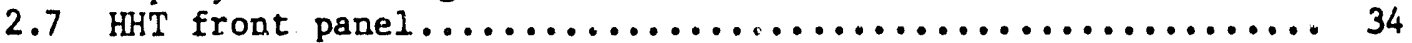

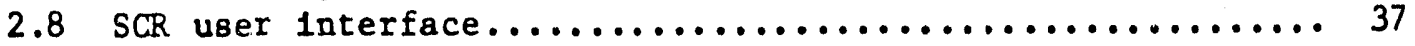

Chapter 2 Tables

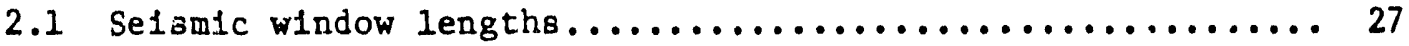

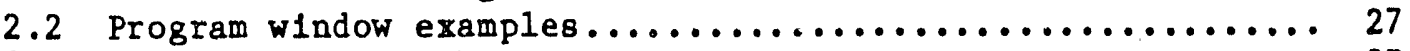

2.3 HHT monitor switch positions.................... 37

Acknowledgments..................................... 42

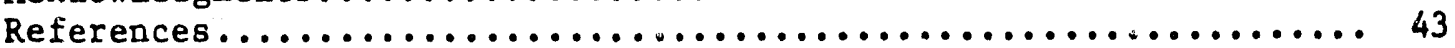

Append1x $A$ : Example of t1me code........................ 


\begin{abstract}
In this two chapter report, Instrumentation used to collect selsmic data is described. Th1s data acquisition system has two parts: 1) portable anolog selsmic recorders and related "Hand-held-testers" (HHT) and 2) portable digitizing untts. During the anolog recording process, ground motion 18 sensed by a $2-\mathrm{Hz}$ vertical-component selsmometer. The voltage output from the selsmometer is split without amplification and Bent to three parallel amplifier circult boards. Each circuit board amplifies the selsmic signal in three stages and then frequency modulates the signal. Amplification at the last two stages can be set by the user. An internal precision clock signal is also frequency modulated. The three data carrier frequencles, the clock carrier frequency, and a tape-speed compensation carrier frequency are summed and recorded on a cassette tape. During the digitizing process, the cassette tapes are played back and the signals are demultiplexed and demodulated. An anolog-to-digital converter converts the signals to digital data which are stored on 8-1nch floppy disks. The complete system response is roughly flat between 2 and $30 \mathrm{~Hz}$ and the approximate ground motion is given by
\end{abstract}

$$
A_{g}(t)=\frac{A(t)}{R_{G L E} R_{S A} R_{V C O} D_{D S C} D_{A D C}}=\frac{A(t)}{(409.6) R_{S A}}
$$

where $A(t)$ is the amplitude response and $R_{G L E}, R_{S A}, R_{V C O}, D_{D S C}$, and $D_{A D C}$ are the amplitude factors of the major components. The recording untt also performs and records a serles of diagnostic tests and callbrations prior to each separate selsmic window. The calibrations provide a complete system callbration scheme and are used to verify the actual galn of each data channel and the operation of the selsmometer.

Programming a selsmic recording unit requires 1) setting channel attenuations, 2) synchronizing the selsmic recorder's internal clock with a time standard such as a master clock, and 3) programing the internal logic to turn on the seismic recorder at predetermined times. The HHT performs two of these functions during programming adfusting the selsmlc recorder's internal clock and setting the selsmic recorder's internal logic. Attenuation is set manually with front-panel knobs. After the selsmic recorders are retrleved, their internal clock "drift rates" are recorded on data sheets. Drift rates for both the HHT and the seismic recorders are entered into the computer and clock-drift corrections are made to the data during data processing. 
Chapter 1: Se1smic-Refraction Data Acquisition System. 


\section{INTRODUCTION}

The U. S. Geological Survey selsmic refraction group in Menlo Park, CA, has operated a portable selsmic-refraction data acquisition system since 1978. Th1s system is used primarily to collect selsmic refraction data, but also has been used to collect wide-angle and near vertical reflection data, time term data, tomographic data, and microearthquake data. The system has two parts: 1) 120 portable analog selsmic recorders and 2) 3 portable digitizing units. A schemetic of the complete system (recorder and digitizer) Is shown in Figure 1.1. John Van Schaack, Gray Jensen, and Robert McClearn, all of the USGS, designed and built the instrumentation in 1978. Healy et al. (1982) describe acquiring, processing, and interpreting the selsmic data collected with this instrumentation.

Each recording unit is approximately 1 cublc foot $\left(0.03 \mathrm{~m}^{3}\right)$ in volume and welghs 50 lbs $(23 \mathrm{~kg}$ ) (F1gure 1.2). Power 1s provided by two rechargeable 6 volt Gel-Cell batteries contalned within the unit. Ground velocity is sensed with a $2-\mathrm{Hz}$ vertical-component selsmometer, and data are recorded on a 30-minute 1/4-inch data-quality analog caseette tape. Recording is 1nitiated by internal logic which has ten programmable data windows and 18 accessed through a 48-pin connector. An external device-- a "hand-held tester" (HHT)-1s used to program the recording unit. A description of progranming with the HHT is given in chapter 2 .

The counter clrcult turns on the recording unit nine minutes, fifty-four seconds before recording selsmic data, allowing it to stabilize. One minute and sixteen seconds before recording selsmic data the, the recording unit performs and records diagnostic tests and calibration signals. Selsmic data wlndow lengths are programmable and determined by the function $2(\mathrm{~N})$ minutes minus 54 seconds, where $\mathrm{N}$ is an integer between 1 and 7 . Hence, the maximum seismic :ecording window is 13 minutes, 6 seconds and the total recording time, including diagnostic tests and calibration signals, is 14 minutes, 22 seconds. Flgure 1.3 displays the recording sequence schematically.

After data acquisition, cassette tapes are played back through the dig1tizlng unit (F1gure 1.4) which demultiplexes, demodulates, and dig1tires the data. Digitized data are formated and written to 8-1nch floppy disks. The digitizer is comprised of several descrete components manufactured by commerclal vendors. All the major component-manufacturers along with their specification manuals are listed in Table 1.4 .

This chapter describes the mafor components of the cassette recorders and the digitizlng units and describes the slgnal response of the complete system. Explanations of the diagnostic tests, callbration signals and the time code are included for completeness. 

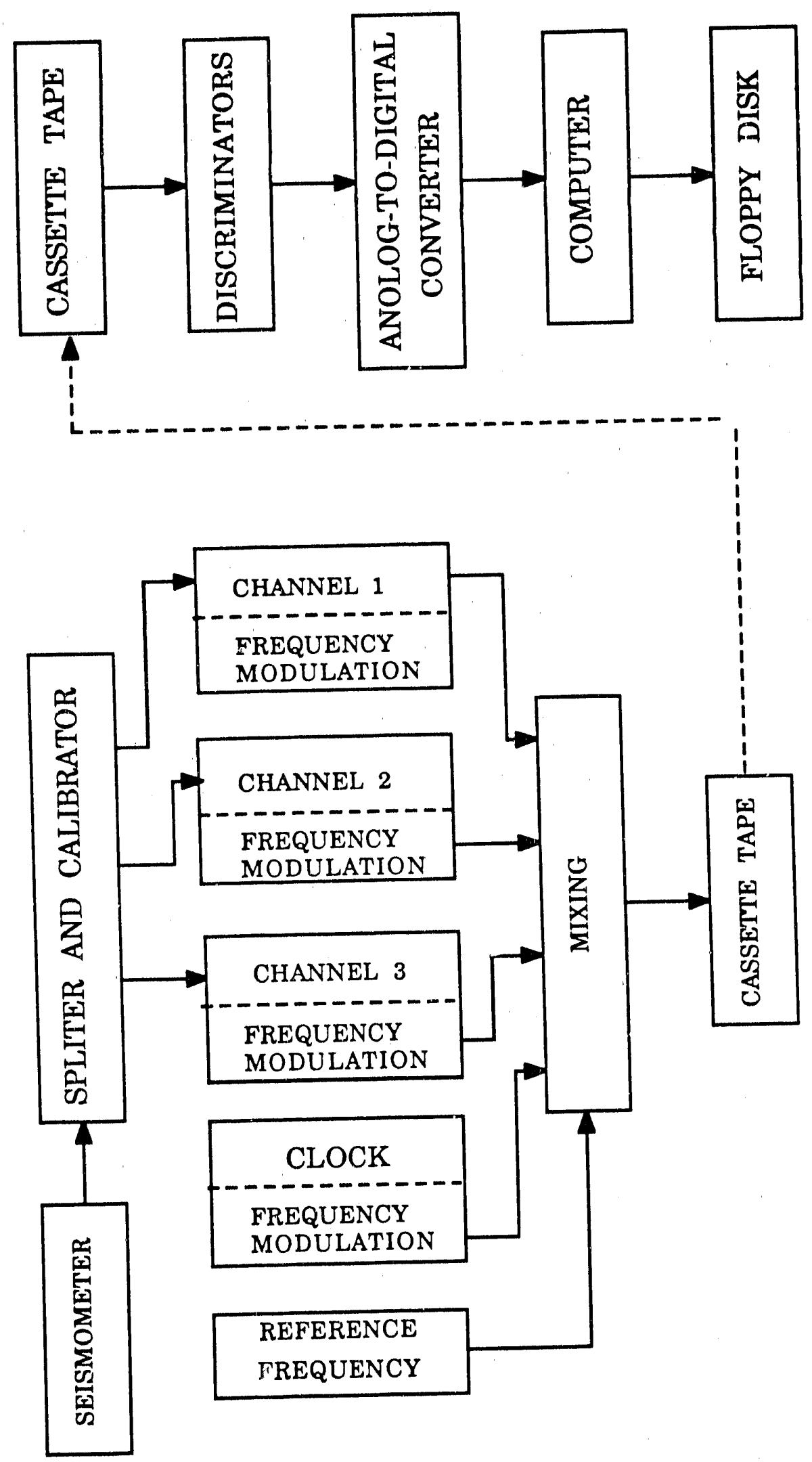

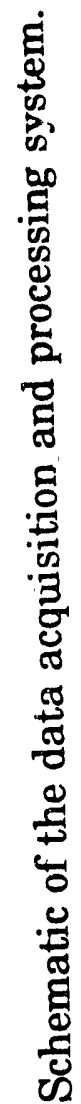



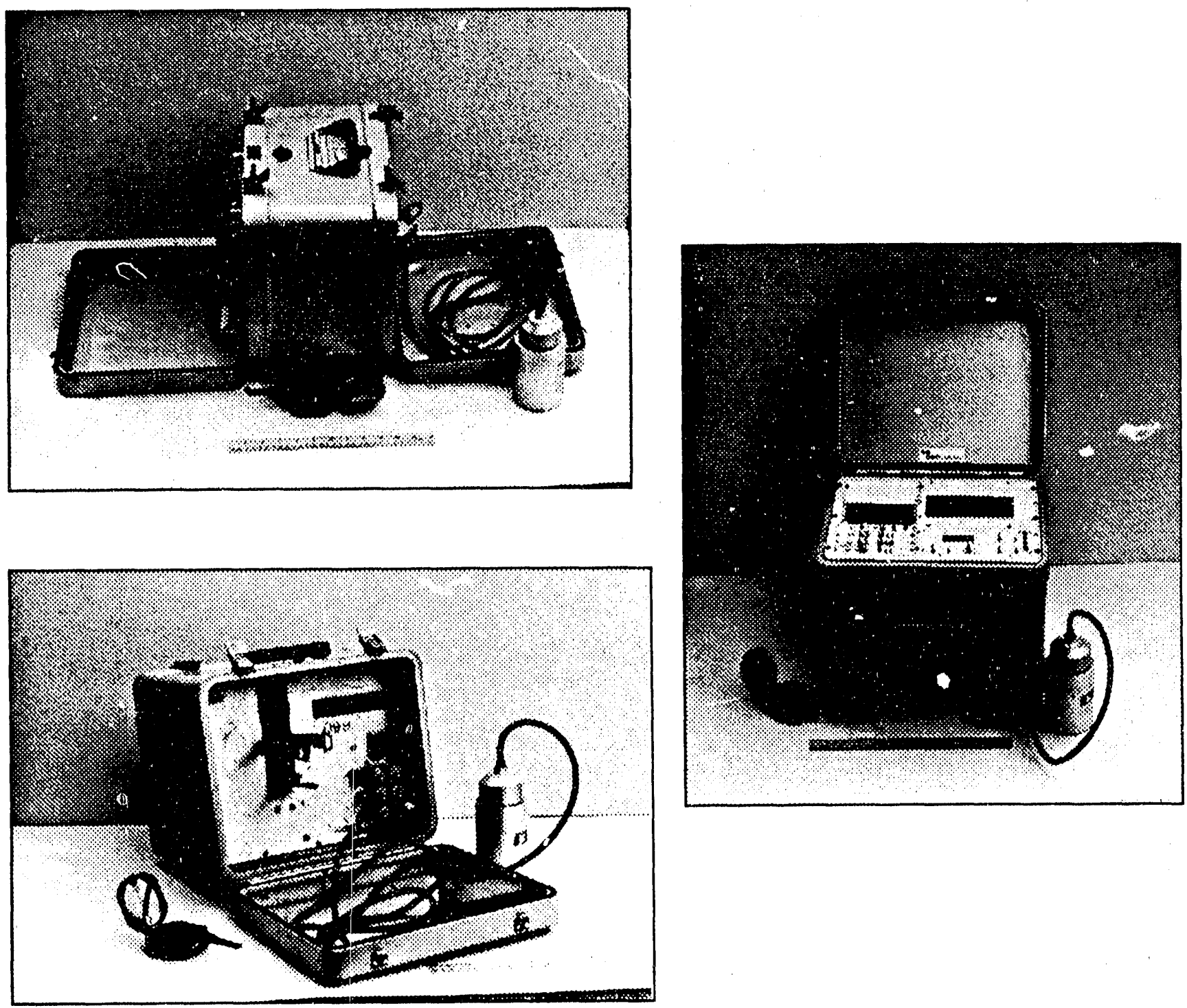

Figure 1.2. Recording unit. 


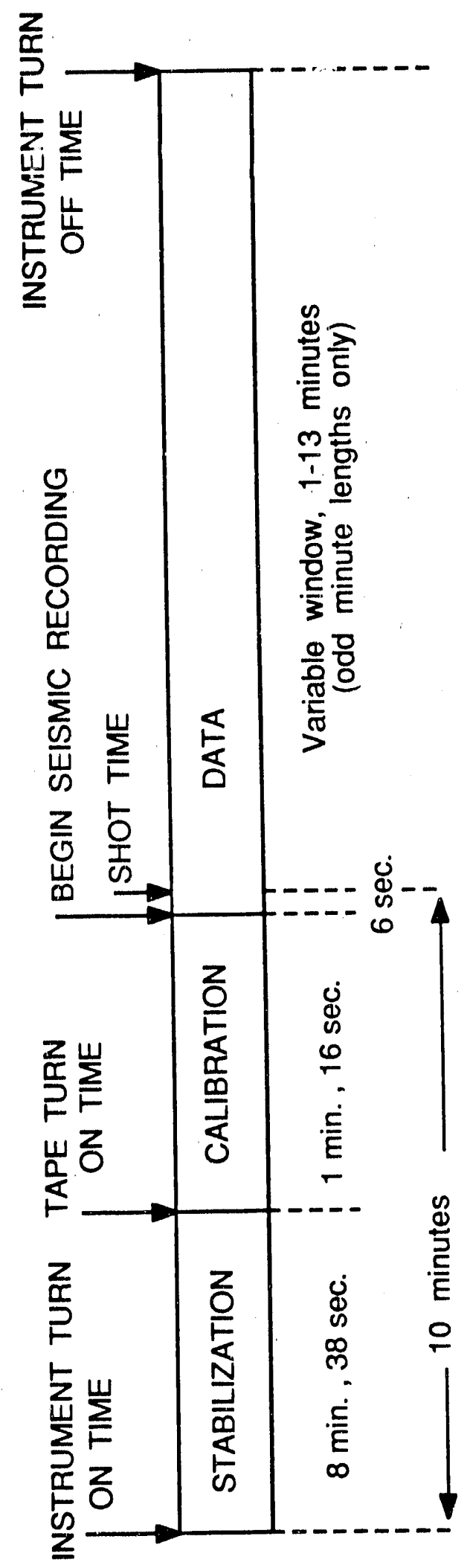

过

엉 등

은 원

O일

¿

Ф

-

- 든 은

당 क क

윤등

등 $E$ 음

. 는 농

范

号

ウே 


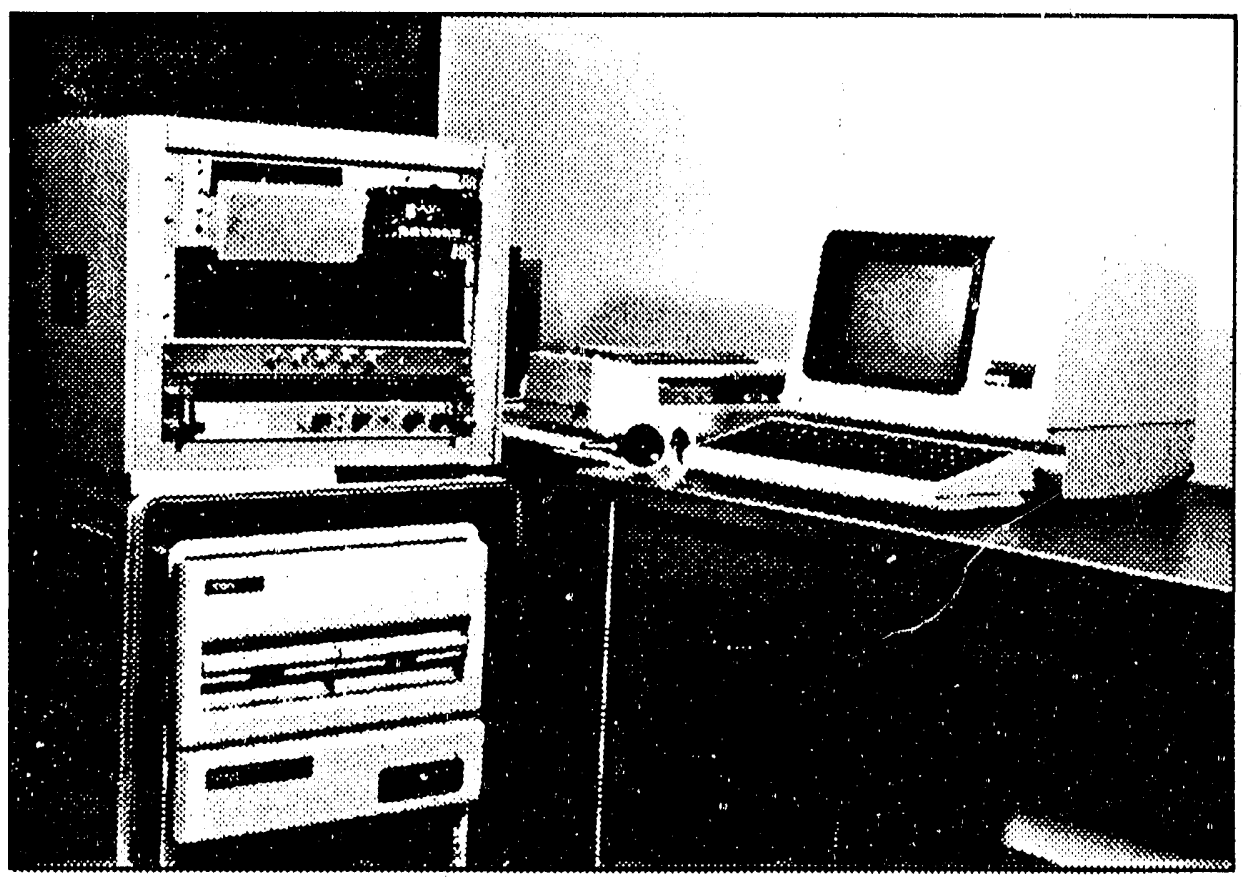

Figure 1.4. Digitizing unit. 


\section{RECORDING UNIT}

The recording unit (F1gure 1.2) is divided 1nto three compartments--two outer operator-accessible areas and an inner compartment where the electronics (F1gure 1.5) are housed. A detachable externally deployed selsmometer is housed in one of the two outer compartments along with selsmometer connectors, a battery recharger connector, and a 48-pin internal logic interface. On the opposite side of the instrument, the other accessible compartment contains the tape deck port, a clock readout (LED), swltches for setting and adjusting the clock, and a set of attenuation switches for each of the three data channels. Manual attenuation of a set gain was the traditlonal manner of recording explosive source data. Following this tradition, the recording units were designed to amplify the signal by $102 \mathrm{db}$ and switches are used to attenuate the signal to a specific amplification. The selsmic signal recorded is affected mainly by the selsmometer, the amplifier, and the voltage controlled osclllator; each of these components is described below.

For each recorder, ground motion is detected by a single Mark ProductsTM $\mathrm{L}-4 \mathrm{~A} 2.0-\mathrm{Hz}(+0.25 \mathrm{~Hz})$ vertical-component selsmometer (Table 1.4). The selsmometer $1 \overline{\bar{s}}$ coupled to the amplifler board by an L-pad resistor network, which adjusts the effective generator constant to a nominal 1 volt per $\mathrm{cm} / \mathrm{sec}$, while providing the proper external damping resistance. The selsmometer is damped at 0.8 critical (nominal). A more detalled description of the selsmometer and L-pad Bystem is given in Eaton (1975).

The output from the selsmometer and L-pad system is split without amplification by a buffer and sent to three amplifler circuit boards (called "channels"). Fach channel has three stages of amplification, with maximum amplifications of $12 \mathrm{db}, 50 \mathrm{db}$, and $40 \mathrm{db}$, respectively (Figure 1.6). Thus, the total gain of the system with the attenuation set to zero is $102 \mathrm{db}$. Attenuations may be selected at both stage 2 and stage 3 . A manual switch ranging from 0 to $54 \mathrm{db}$, in $6 \mathrm{db}$ increments, controls attenuation at stage 2 . At stage 3 , attenuation of $0,20 \mathrm{db}$, or $40 \mathrm{db}$ is selected w1th a second switch. The total gain of each channel is the sum of the galns of each stage, where the galn at each stage is the maximum gain minus the attenuation. For example, a channel with an attenuation setting of $48 \mathrm{db}$ at stage 2 and an attenuation setting of $20 \mathrm{db}$ at stage 3 would have a total gain of $34 \mathrm{db}$.

$$
\begin{aligned}
& \text { stage } 1 \\
& 12 \mathrm{db}
\end{aligned} \underset{[50-48] \mathrm{dtage}}{2}+\underset{[40-20] \mathrm{db}=34 \mathrm{db}}{\text { stage } 3}
$$

The total gain of any channel can be derrived from the callbration signals recorded after the instrument stabilization perlod and before the seismic data. These callbration signals are discussed in the diagnostics and calibration section.

After amplification the signal is converted from voltage to frequency (frequency modulation) by a voltage controlled osclllator (VCO). Center frequencles for channels 1,2 , and 3 are $680 \mathrm{~Hz}, 1020 \mathrm{~Hz}$, and $1360 \mathrm{~Hz}$, respectively. For a maximum voltage deviation of \pm 5 volts, the maximum 


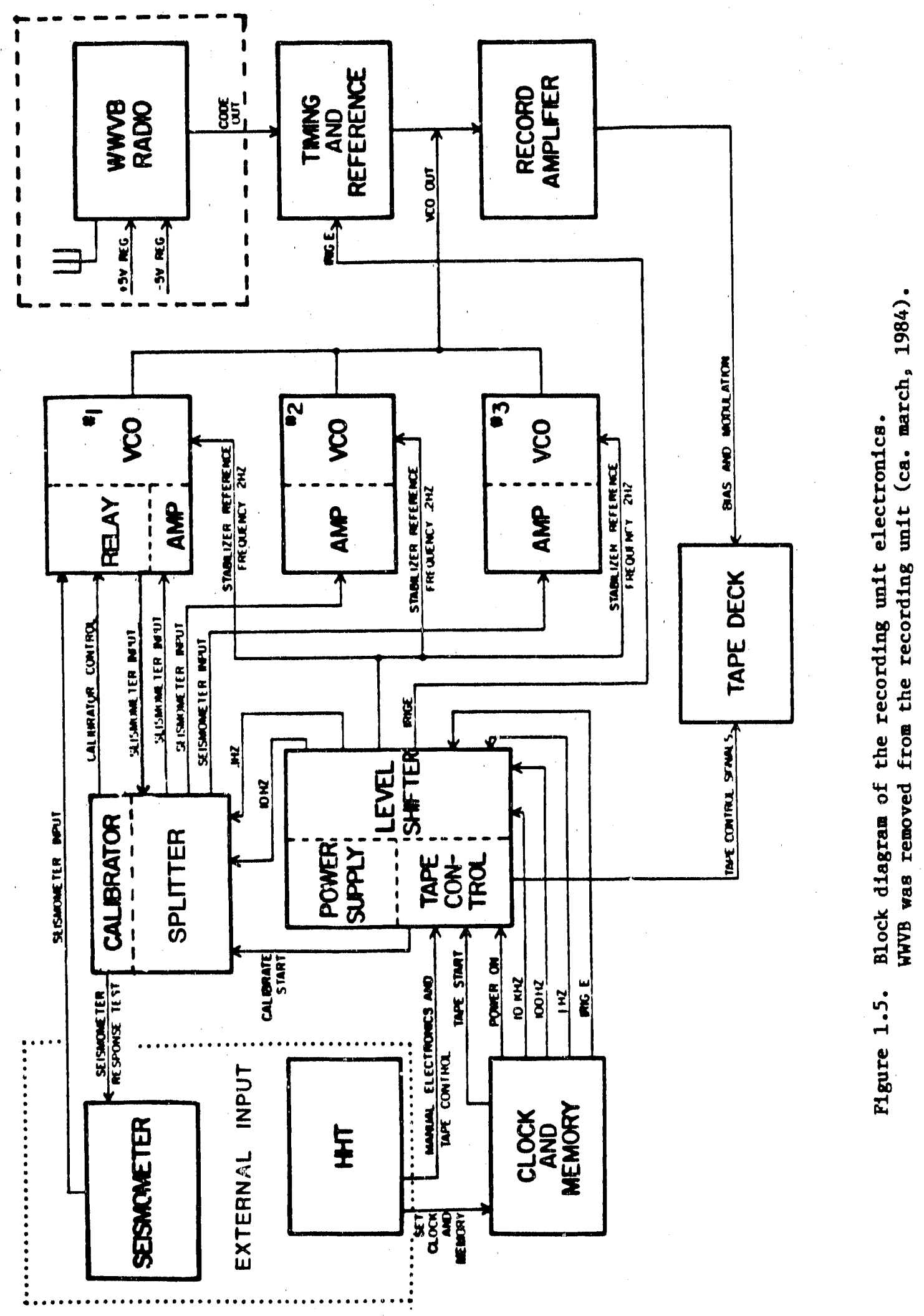




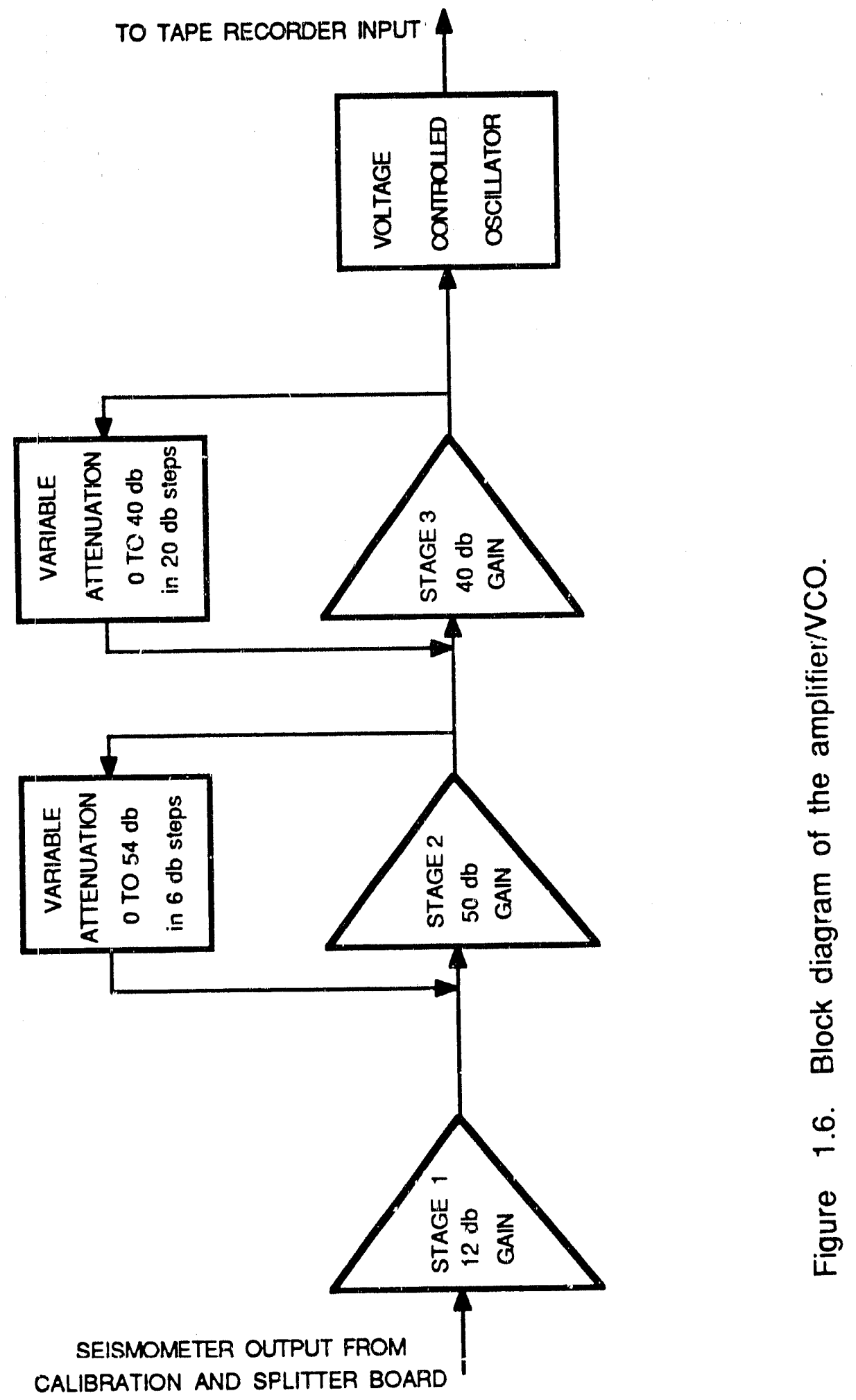


frequency devlation $18+125 \mathrm{~Hz}$. The center frequencles are referred to as carriers of a channel. Calibration of the VCO is not performed independently, but is part of the system calibration discussed in the diagnostics and callbration section.

The t1me standard for each unit is provided by a Vectron LaboratoriesTM (Table 1.4) model 252-1631 crystal oscillator. The internal quartz crystal oscillates at $1 \mathrm{MHz}$ and $1 \mathrm{~s}$ frequency adjustable within the range $\pm 5 \mathrm{~Hz}$ (5 parts per million). The unit is temperature compensated with an accuracy of \pm $1 \times 10^{-7}$ ( 1 part per $10 \mathrm{~m} 1111 \mathrm{on}$ ) for the temperature range $0^{\circ} \mathrm{C}$ to $50^{\circ} \mathrm{C}$. This stability corresponds to less than 10 milliseconds error per day. After the instruments are retrleved from the fleld, drift rates for each instrument are measured agalnst a more stable master clock, which 1s periodically synchronlzed with the world wide standard, WWV. Following the manufacturer's practice, we assume a linear drift rate between the time the clock is set and the time it's drift is measured and correct the data during the digitizing stage. When an 1nstrument drift of more than 50 milliseconds 18 recorded during any given deployment (approximately 36 hours), the clock unit is adjusted.

IRIG E, the serial time code output of the clock unit, is frequency modulated on a $3500 \mathrm{~Hz}$ carrier with a maximum deviation of $\pm 50 \mathrm{~Hz}$. The three data carriers, the clock carrier, and a tape-speed compensation reference carrler of $4687.5 \mathrm{~Hz}$ are summed and recorded in analog form with a Ph1-Deck TM cassette magnet1c tape deck. The reference carrier is derived from a MondtorTM ('Table 1.4) quartz crystal osclllator which is set at at $2.400 \mathrm{MHz}+0.006 \%$ (6 parts per 100 thousand) between the temperatures $0^{\circ} \mathrm{C}$ and $30^{\circ} \mathrm{C}$. Thus, the accuracy of the reference frequency is $\pm 144 \mathrm{~Hz}$ over this temperature range.

\section{DIGITIZING UNIT}

USGS-designed digitizing systems retrleve and digitize the recorded data (F1gure 1.7). These systems are controlled by Digital Equipment Corporation (DEC)TM PDP-11/23 computers with RT11 operating systems. They contaln a Tr1ple I Ph1-DeckTM cassette tape drive w1th tape-speed compensation, TRI-COMTM discriminators, a DatumTM time code translator, a DRV1l parallel line 1nterface, and a DEC ADV11-C 12 b1t analog-to-digital converter (ADC). For each component Table 1.4 lists the manufacturers and the specifications. The analog slgnal read by the tape deck goes to a bank of 5-pole TRI-COMTM 502 FM discriminators. Each discriminator, except the reference discriminator, bandpass filters the carrier signal about a separate center frequency and converts the FM signal back to voltages. As in the recorders, center frequencles are $680 \mathrm{~Hz}, 1020 \mathrm{~Hz}$, and $1360 \mathrm{~Hz}$ for data channels 1,2 , and 3 , respectively, and $3500 \mathrm{~Hz}$ for the time-code channel. The width of the bandpass filter for each data channel is $250 \mathrm{~Hz}$ which equals the maximum frequency deviation in the recorders. To allow for better resolution of the time signal, a band width of $500 \mathrm{~Hz}$ is used. The tape-speed-compensation discriminator demultiplexes the reference frequency of approximately $4687.5 \mathrm{~Hz}$ 


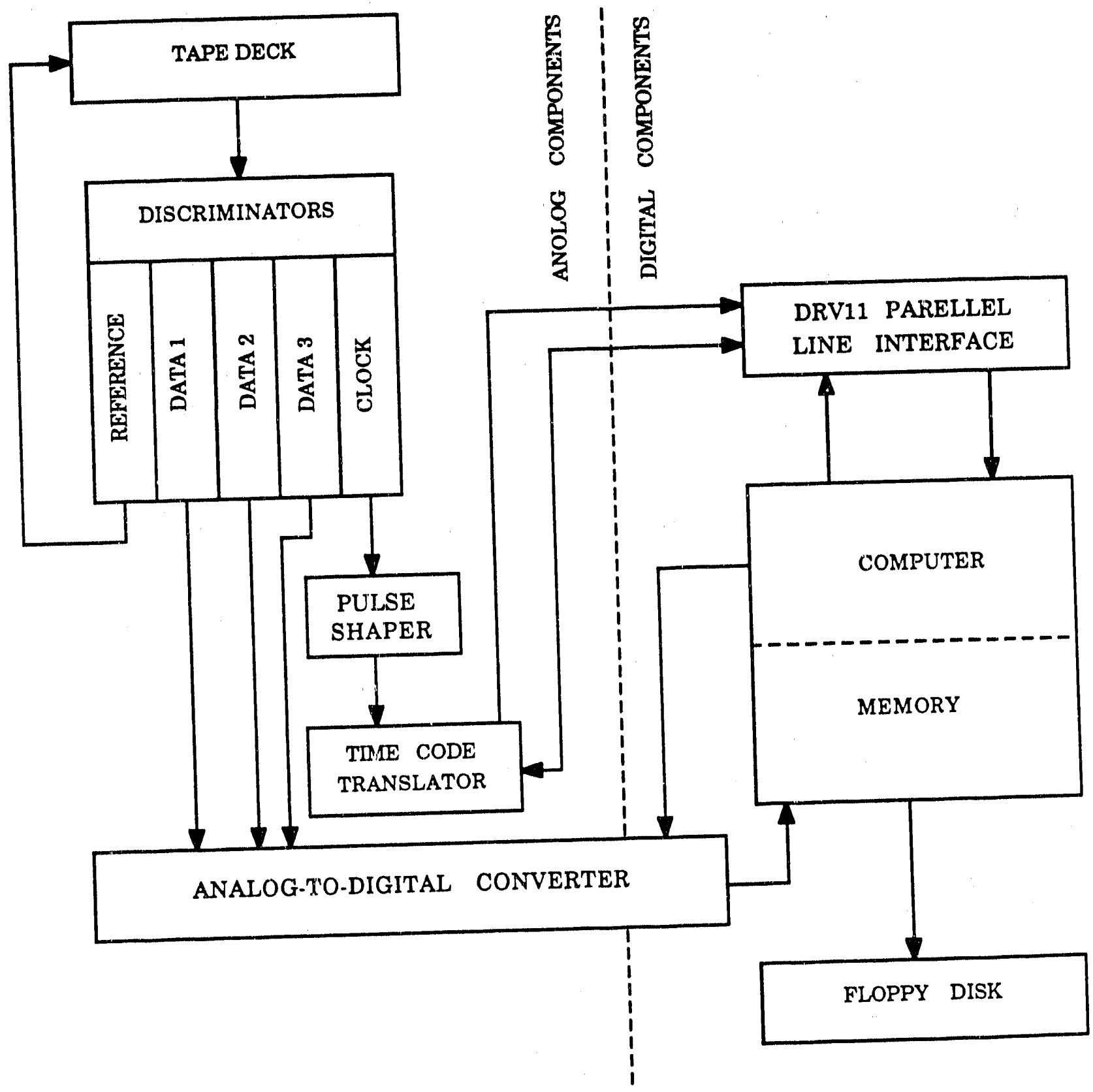

Figure 1.7. Diagram of the digitizing unit. 
and sends it to the tape-speed-compensation clrcult and to each of the data discriminators. The reference frequency sent to the tape-speed-compensation c1rcult is compared to a frequency of $4687.5 \mathrm{~Hz}$ generated locally by another MonitorTM (Table 1.4) quartz-crystal oscillator. To match the reference frequency from the tape to this local standard, the tape speed compensation circult continuously adjusts the speed of the tape deck ("capstan compensation"). Thus, the tape 18 played back at nearly the same speed it was recorded, preventing accldental shifting of the data-carrier frequencles. The tape-speed-compensation signal sent to the data discriminators is combined with the data signal through a process called "subtractive compensation". Subtractive compensation removes most of the system nolse produced by rapid tape-speed fluctuations.

After the time cole 18 converted back to a voltage, it is sent to a DatumTM time-code translator, where $1 \mathrm{t}$ is decoded and a 200 pulse per second signal is generated. The decoded time signal is transmitted continuously to the computer using the bit map shown in Figure 1.8. In order to decode the time, the translator must read at least 10 seconds of the code. Once the translator decodes the time, it compares and updates the time every $0.1 \mathrm{~s}$. If the time code deteriorates, the translator must complete the next readable ten-second time-code frame before it again transmits synchronized time to the computer. Thus, for a single read-error, there may be up to 20 seconds between synchronized time signals to the computer. During this time, an error flag is set (ERR, Figure 1.8). In addition to signal-level errors, the time code translator compares successive $10 \mathrm{sec}$ frames to determine whether the time code is decoding correctly. If the translator detects an error, $a$ non-synchronization flag 1 s set and an error flag (ERR, Figure 1.8) 1s set.

For input deviations of $-125 \mathrm{~Hz}$ and $+125 \mathrm{~Hz}$ about the center frequency, the data discriminators, channels 1,2 , and 3 , produce voltages between -5 and +5 volts, respectively. These voltages are input to a DEC ADVII-C ADC in bipolar mode (via single-ended inputs), where they are converted to digital data in offset-binary format. In octal, the outputs from the ADC are: 000000 at -5.0 volts, 004000 at 0.0 volts, and 007777 at +4.9975 volts. In base 10 , Input voltages of $-5.0,0.0$, and +4.9975 are output as 0,2048 , and 4095 digital counts, respectively, or about $2.44 \mathrm{mv} /$ count. Digitizing is lnitiated under program control by setting the $A D C$ start bit in the control/status register. The time code translator sends the 200 pulse per second signal to the computer through the DRVII parallel line interface. This signal is input to $R E Q B$ which is polled by the computer. Each time a pulse is generated, the computer digitizes a sample on each data channel. The digltized data are stored on 8-inch floppy disks with a maximum storage capacity of 5 Mbytes. Thus 1t is posetble for each disk to store 61 separate selsmic traces assuming $20 \mathrm{sec}$ of data per trace and a sample rate of 200 samples per second.

\section{SYSTEM RESPONSE}

Because tape-speed fluctuations during playback limit the dynamic range of each channel to $25 \mathrm{db}$, subtractive compensation is used to snhace the signal 


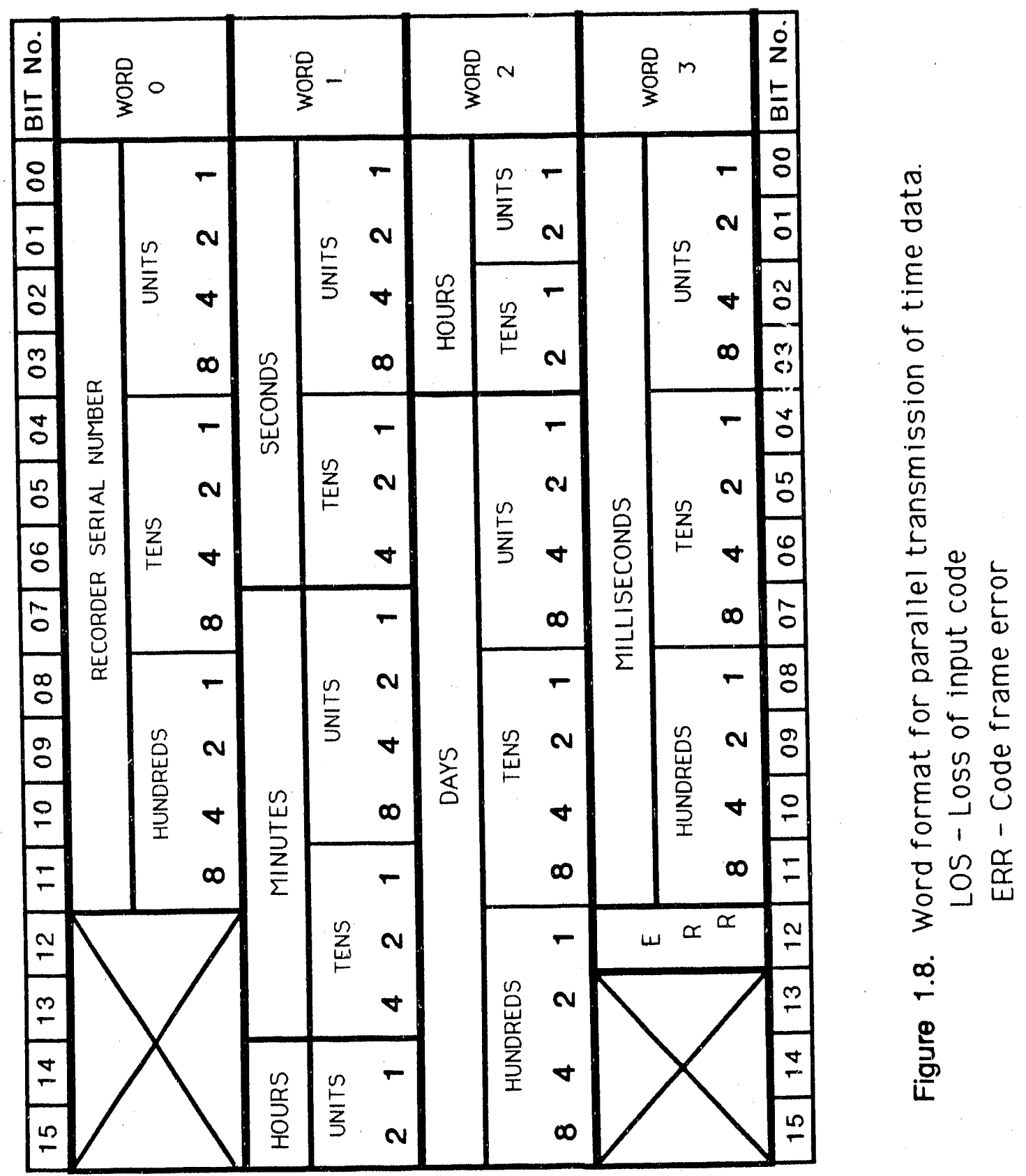


and widen the dynamic range as described above. With subtractive compensation, each channel has a dynamic range of about $48 \mathrm{db}$. Channel at tenuations are usually set $18 \mathrm{db}$ apart so that the dynamlc ranges overlap. For example, a typical set of attenuations is $12 \mathrm{db}, 30 \mathrm{db}$, and $48 \mathrm{db}$ for channels 2, 1 , and 3 , respectively. Therefore, the gain of each channel is $90 \mathrm{db}, 72 \mathrm{db}$, and $54 \mathrm{db}$, respectively, and Indvidual channel dynamic ranges are 42-90 db, 24-72 db, and 6-54 db, respectively. In this example, the effective dynamic range of the system is $84 \mathrm{db}$ and at any level within this range the signal-to-noise ratio is acceptable.

The recording system velocity response 18 roughly flat between 2 and 30 $\mathrm{Hz}$. At low frequencles the response is determined by the geophone, which has a corner frequency of $2 \mathrm{~Hz}$. The response rolls off at $12 \mathrm{db} /$ octave between 2 $\mathrm{Hz}$ and $0.1 \mathrm{~Hz}$ and at $24 \mathrm{db} /$ octave below. $0.1 \mathrm{~Hz}$ (J. Van Shaack, oral comm., 1987). Character1st1cs of the amplifler and VCO determine the low-pass frequency response. This response 1s similar to a 2-pole Butterworth filter with a corner frequency of $30 \mathrm{~Hz}$ and a rolloff of $12 \mathrm{db} /$ octave (J. Van Shaack, oral comm., 1987). Corner frequency is deflned as the point where the response 1 s $3 \mathrm{db}$ below the maximum.

If the frequency response of each component is approximated by a theoretical transfer function, the frequency response of the complete system (recorder and digltizer) may be described by the product of the individual component transfer functlons (Healy and $0^{\prime} \mathrm{Ne11}, 1977$; Stewart and $0^{\prime} \mathrm{Ne11}$, 1980; Dratler, 1980). With this method, the program KESPONSE (Stewart and 0 Ne1l, 1980) computes amplitude and phase spectra from parameters that describe the frequency response of each component. The selsmometer and L-pad, J402 amplifier and VCO, and Tri-Comm descriminators used in this system are among several types of components analyzed by Dratler (1980) and Stewart and 0'Neil (1980). Parameters for the components are given by Stewart and $0^{\prime}$ Neil (1980) and are reproduced here in Table 1.1. Although the ADC was not analyzed speclfically, Stewart and $0^{\prime}$ Nell state that ADC's generally have no relevant poles and, therefore, that only the conversion factor $(2.44 \mathrm{mV} / \mathrm{count})$ need be included. The amplitude response factor of the ADC is listed in Table 1.2. Figure 1.9 (from Dawson and Stauber, 1986) shows the amplitude response curves derived from analysis of the system with the RESPONSE program (modified by $P$. Dawson). Because the amplitude reponse, $A(t)$, is relatively 1 Lat for the frequencles between $2 \mathrm{~Hz}$ and $30 \mathrm{~Hz}$, it may be approximated by a simple equation combining the products of ground velocity, $A_{g}(t)$, and the amplitude factors of the major components:

$$
A(t)=\left[R_{G L E} R_{S A} R_{V C O} D_{D S C} D_{A D C}\right] A_{g}(t)
$$

where

$\mathrm{R}_{\mathrm{GLE}}$ is the effective generator constant of the selsmometer and $\mathrm{L}$-pad $(\mathrm{V} / \mathrm{cm} / \mathrm{s})$.

$\mathrm{R}_{\mathrm{SA}} \quad$ is the system amplification (gain, V/V).

$\mathrm{R}_{\mathrm{VCO}}$ is the deviation sensitivity of the VCO $(\mathrm{Hz} / \mathrm{V})$.

$D_{\text {DSC }}$ is the deviation sensitivity of the discriminator $(\mathrm{V} / \mathrm{Hz})$.

$D_{A D C}$ is the sensitivity of the $A D C$ board (counts/V). 

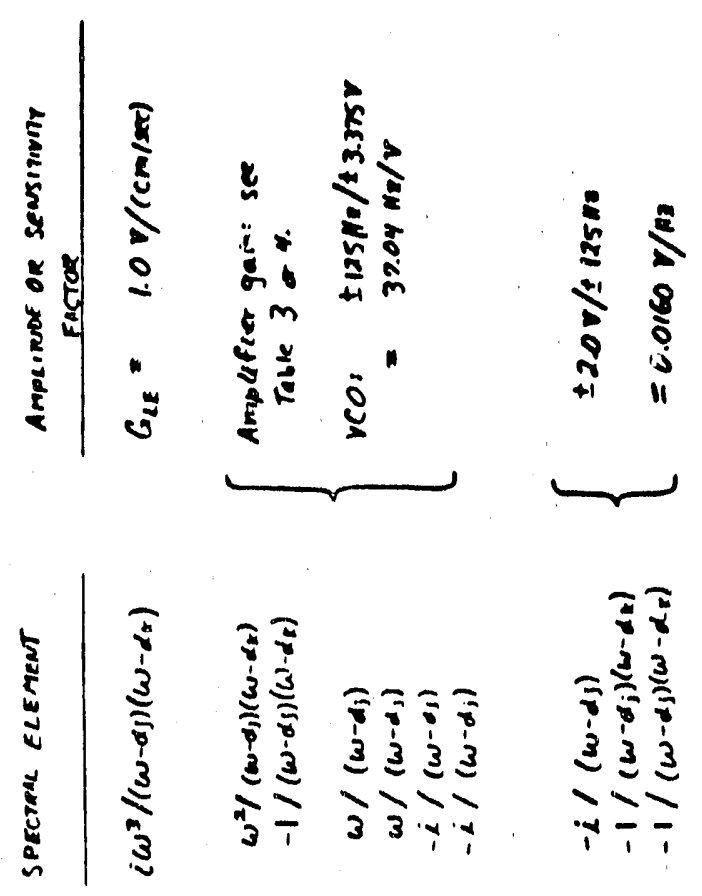

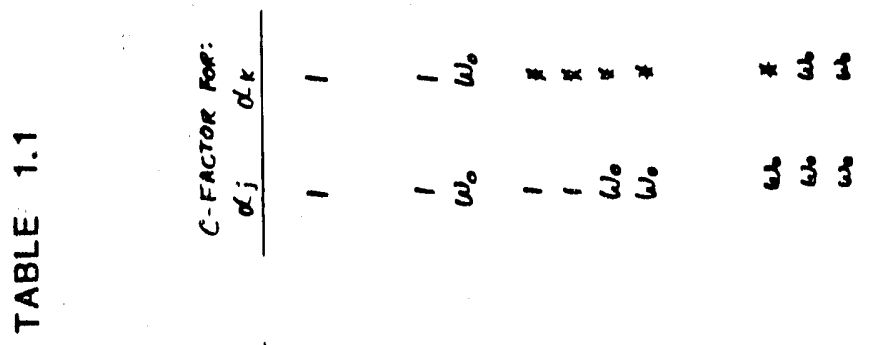

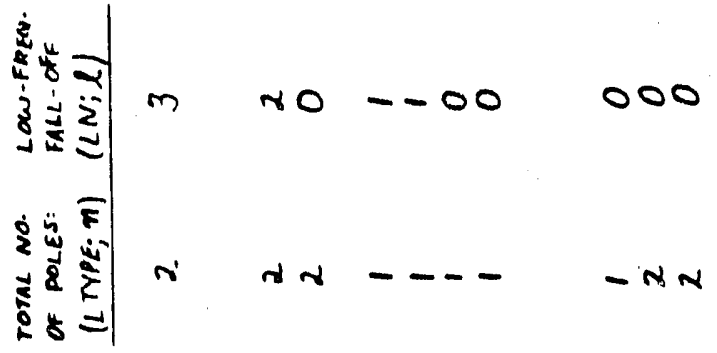

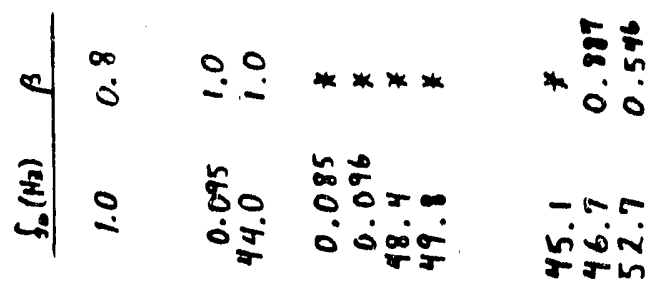

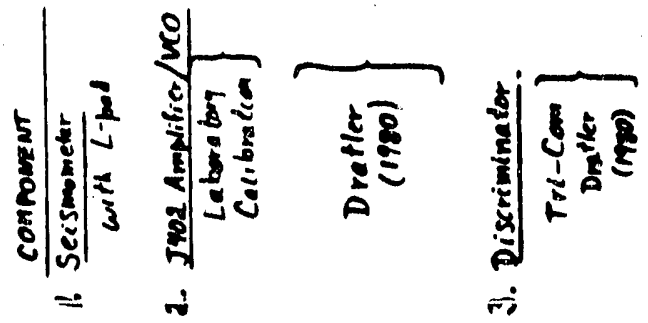




\section{TABLE 1.2}

\begin{tabular}{l} 
component \\
\hline$R_{\text {GLE }}$ \\
$R_{S A}$ \\
$R_{V C O}$ \\
$D_{D S C}$ \\
$D_{A D C}$
\end{tabular}

value $\overline{\mathrm{l}} \mathrm{v} / \mathrm{cm} / \mathrm{sec}$ dimensionless galn varlable $\mathrm{V} / \mathrm{V}$ $25 \mathrm{~Hz} / \mathrm{V}$ $0.04 \mathrm{~V} / \mathrm{Hz}$ 409.6 counts/V

Table 1.3

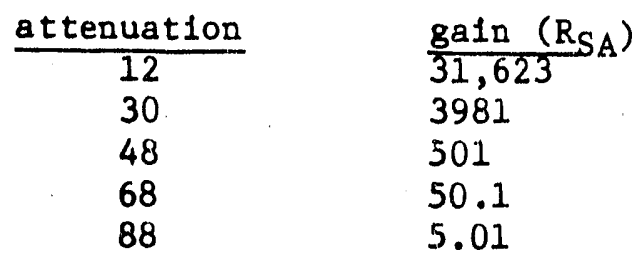




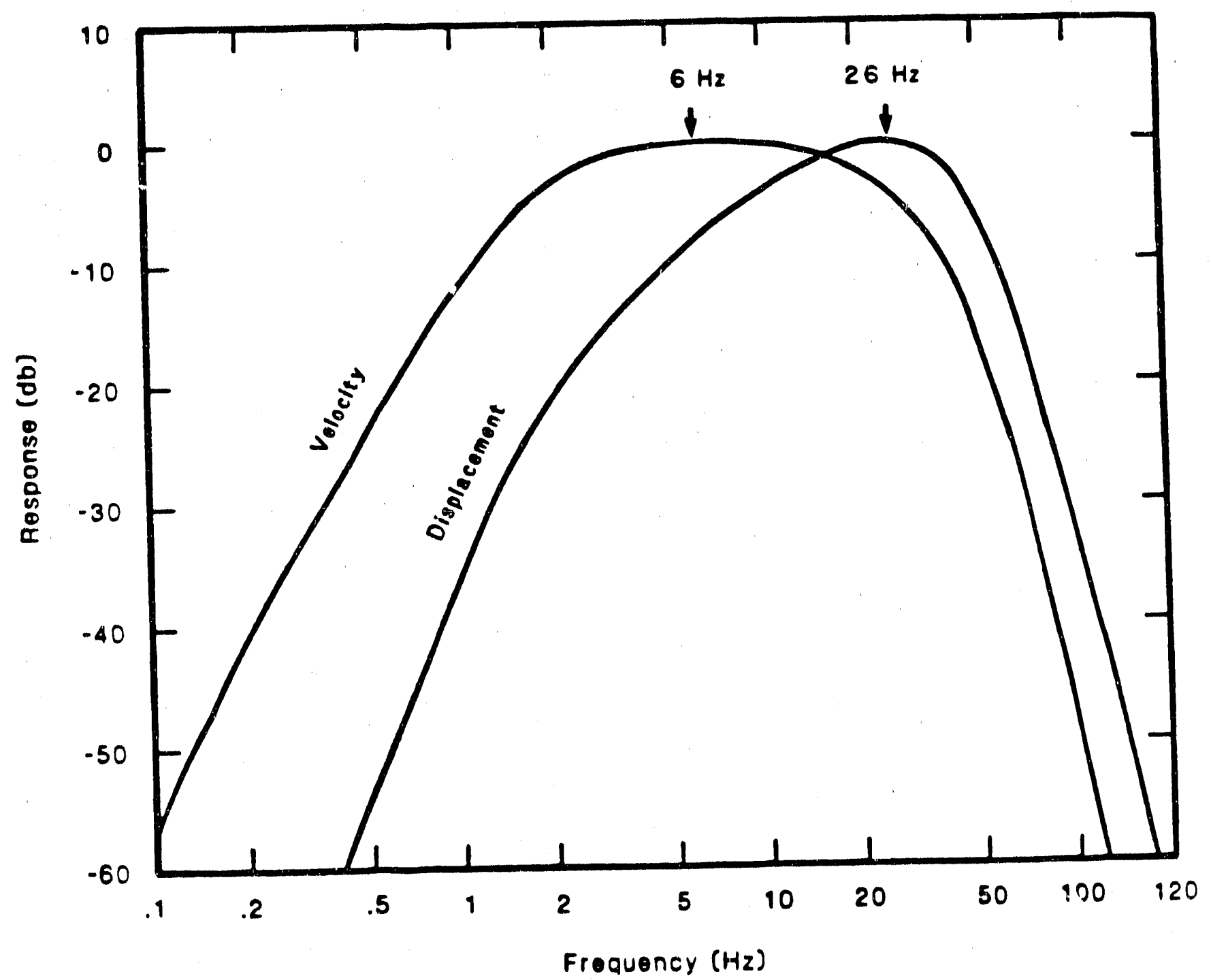

F1gure 1.9. Theoretical Transfer-function curves for the USGS short-period selsmic refraction system (both recorder and digitizer). Solid ines are the displacement and velocity normalized amplitude. (From Dawson and Stauber, 1986) 
Values for Individual components are 11sted in Table 1.2. The system gain $\left(R_{S A}\right)$ varies for each channel of each instrument and 18 determined by the equation:

$$
R_{S A}=10^{\left(\frac{102-a}{20}\right)}
$$

where " $a$ " is the attenuation setting. Some commonly used gains are listed in Table 3 .

Thus approximate ground motion 18 given by:

$$
A_{g}(t)=\frac{A(t)}{R_{G L E} R_{S A} R_{V C O} D_{D S C} D_{A D C}}=\frac{A(t)}{(409.6) R_{S A}}
$$

Dawson and Stauber (1986) use this method to calculate approximate ground motion from recorded selsmograms.

\section{DIAGNOSTICS AND CALIBRATION}

After a stabilization period lasting 8 minutes 38 seconds, the recording unit performs a series of diagnostic tests and callbrations lasting 1 minute, 15 seconds. These signals are recorded on the cassette tape prior to the selsmic recording (Figure 1.10). These records are used to help diagnose instrument fallures. Prior to subsequent deployment, malfunctioning Instruments are repaired. The diagnostic and callbration sequence consists of a selsmometer pulse, an amplifier step, and 10-Hz sine-wave calibration signals at $1,10,100$, and 1000 microvolts RMS. The selsmometer pulse indicates the frequency response of the geophone and reveals malfunctions of the selsmometer. Amplifler frequency response and malfunctions may be diagnosed using the amplifler step portion of the diagnostics.

Finally, during the $10-\mathrm{Hz}$ callbration test, four separate voltage levels are recorde These voltage levels are digltized along with the selsmic data and from the.d galn levels can be verlfled and refined. In designing the refraction data-acquistion system, 1t was recognized that many parts of the system affect the final recorded signal. This complexity makes calibrating the final signal by calibrating individual parts difficult and unreliable. Hence, the four sine-waves are used to provide a complete system callbration scheme. The actual digitized calibration signal is not saved only the mean peak-to-peak amplitude (1n digltal counts) is saved for each separate RMS voltage level. In order to calculate the actual galn, the system response equation is used, the unknown being $R_{S A}$. Thus,

$$
R_{S A}=\frac{A(t)}{\left[R_{V C O} D_{D S C} D_{A D C}\right] A_{C A L}(t) 2 \sqrt{2}},
$$

where $R_{V C O}$, $D_{D S C}$, and $D_{A D C}$ are defined as given in the system response 


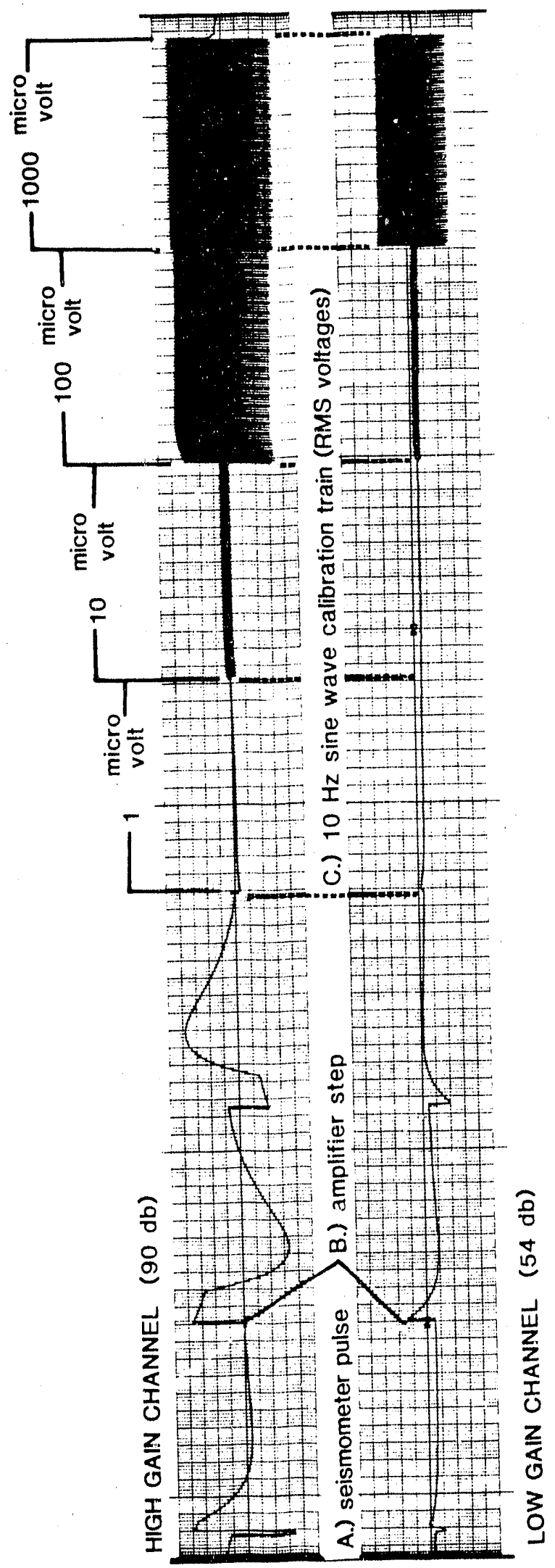

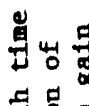

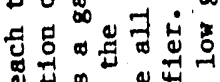

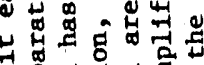

自这㝴式是出

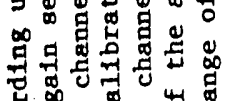

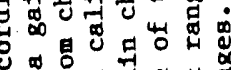

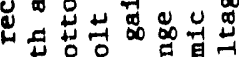

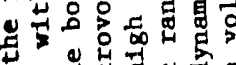

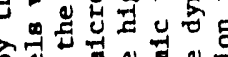

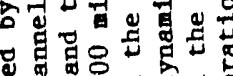

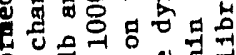

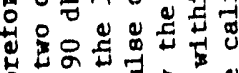

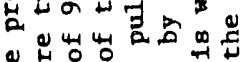

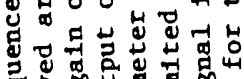

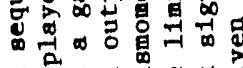

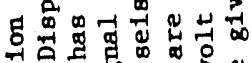

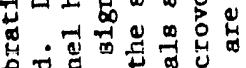

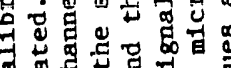

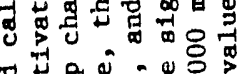

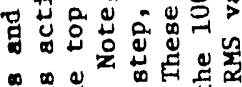

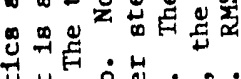

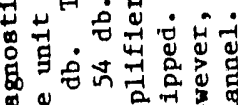

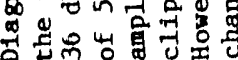

0
-1
-1
0
0
0
0 
section. ACAL $(t)$ is the RMS amplitude of the calibration signal in volts, and 2 is a multiplier used to convert RMS amplitude to peak-to-peak

amplitude for a sine wave. $A(t)$ is the mean peak-to-peak amplitude of the digltized sine wave.

\section{TIME CODE}

Universal Coordinated Time (UTC) is recorded on the cassettes as an IRIG-E signal, multiplexed with other signals as described above. IRIG-E is a "binary-coded-decimal" (BCD) serlal time signal originally designed for NASA telemetry. It encodes time as a serles of signal-level shifts which begin at an exact UIC time and persist for one of three periods: "wide", "medium", and "narrow". In IRIG-E, these pulses occur every 0.18 and are 80,50 , and $20 \mathrm{~m} 3$ long, respectively. Wide pulses are used to mark reference points in the time code. Each 1-8 point is preceded by a single wide pulse, and each 10-s point is bracketed by two wide pulses (Figure 1.11A). Thus, two types of time frames are defined: 1) a 1-s frame and 2) a 10-s frame.

Within each 1-s frame ( 10 pulses in IRIG-E), up to two decimal digits are encoded using medium pulses for ones and narrow pulses for zeros. A narrow divider pulse separates the first decimal digit, encoded in the first four successive pulses, from the second decimal digit, encoded in the remaining successive pulses. The BCD code used is simply a 4-bit unsigned binary number In the range $0000_{2}=0_{10}$ to $1001_{2}=910$. The bits are in reverse order, low-order bit first. For example, a code of 1010 represents $0101_{2}=5_{10}$. The 4-pulse groups and their signiflcance for IRIG-E are shown in Figures $1.11 \mathrm{~B}-\mathrm{G}$. Appendix A describes a method of reading IRIG-E in base 10 from plots.

Beause wide pulses are used to mark reference points and each 1-8 frame contalns a divider pulse, the entire ten pulses per second 18 never used for coding. Each 1-s frame uses at most 8 pulses for encoding information and in the first second frame after a ten second point, only 7 pulses are available for encoding. The later 18 possible because the seconds digit in the tens position never exceeds $101_{2}=510$ (50 8; Figure 1.10B).

The time encoded with these digits is the UTC time of the starting point for that 10-s frame. It is given as Jullan days, mlnutes, and seconds. A fully encoded UTC time is recorded in each 10-s frame, along with the serial number of the recorder. The time-code translator synchronizes to this code and then updates 1ts output continuously to reflect the (anticlpated) UTC time at that point in the coded signal. Disagreement between this anticipated time and subsequently translated BCD codes cause a "synchronization" error as described above. 


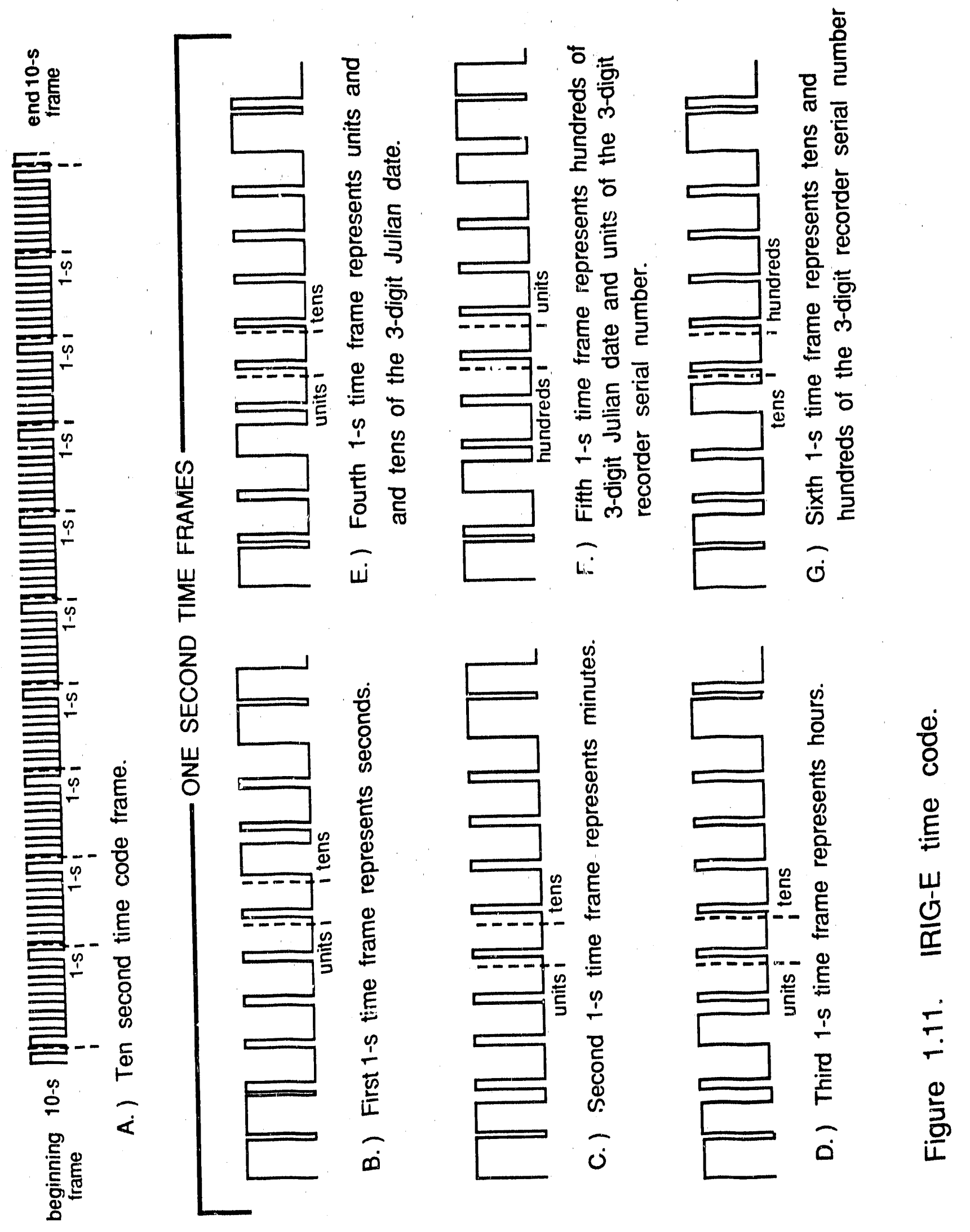


Table 1.4

MANUFACTURERS OF THE MAJOR COMPONENTS

Mark Products, Inc.

10507 Kinghurst Dr.

Houston, Texas 77099

(713) 498-0600

specification: L-4A $1.0 \mathrm{~Hz}$ and $2.0 \mathrm{~Hz}$ land or borehole geophone

Vectron Laboratorles, Inc.

166 Glover Ave.

Norwalk, Connecticut 06850

(203) $853-4433$

spec1fication: CO-251 through C0-256; TCXO

Monitor Products Company, Inc.

P.0. Box 1966

Oceanside, California 92054

(619) 433-4510

specification: quartz crystal osclllator

Triple I, Inc.

4605 North St1les

P.0. Box 18209

Oklahoma C1ty, Oklahoma 73118

(405) 521-9000

specification: Phl-deck cassette tape deck

Tr1-Com, Inc.

7304 Grove Road

Fredr1ck, Maryland 21701

(301)694-6666

specification: Model 502 FM discriminator

Datum, Inc.

1363 S. State College Boulevard

Anaheim, California 92806

(714) 533-6333

specificat1on: Model 921.0 Time code Translator Part number 9210-716 
Table 1.4 (continued)

MANUFACTURERS OF THE MAJOR COMPONENTS

Digital Equipment Corporation

Maynardver Ave.

Maynard, Massachusetts 06850

(617) 897-5111

specification for ADC and DRVII parellel line interface:

PDP-11 M1crocomputer Interfaces Handbook 
Chapter 2: Selsmic Cassette Recorder Users Gulde 


\section{INTRODUCTION}

The selsmic cassette recorders (SCR) are used to record selsmic data in analog form. In order to program these instruments, two other instruments -a master clock (tIme reference) and a hand held tester (HHT) - are used to synchronize the SCR internal clock and set the recording parameters. The same type of clock used in the recording units is used in the HHT. Because these clocks are not accurate enough, a master clock is used as the time reference. The master clocks drift less than 1 ms per week and are perlodically checked against a universal time standard relayed by satellites.

Programming a SCR requires 1) setting channel attenuations, 2) synchronizing the SCR's internal clock with a time standard such as a master clock, and 3) programming the internal logic (hereafter called the memory) to turn on the SCR at preset times. The hand held tester (HHT) performs two of these functions during programming -- adjusting the SCR's internal clock and loading the SCR's memory. To synchronlze the SCR's clock with the time standard, first, the HHT's clock is synchronized with a master clock, then the SCR's clock is synchronized with the HHT's clock. While this procedure introduces a drift from the HHT's clock, the drift is small because the programming perlod 1s short. Before loading the SCR's memory, the HHT's memory must first be programed. The turn on times and recording durations are then transmitted via a 48-wire cable to the SCR's memory. During a normal programming session, the HHT 18 programmed first (memory and clock), then it is used to successively program each of the SCRs. After the last SCR is programed, the HHT is again compared to the master clock to determine the drift of the HHT clock during programming. As discussed in the "recording unit" section, after the SCRs are retrieved, their drift times are recorded on data sheets. The proceedure used to measure the drift is similar to that used to synchronize the SCR's clocks. Drift times for both the HHT and the SCRs are entered Into the computer and a drift time correction is made to the data during data processing.

In order to communicate programming procedures to readers unfamilar with these devices, varlous terms will first be defined and discussed, followed by a description of SCR and HHT controls. Programming procedures will be given last.

\section{DEFINITIONS AND GENERAL INFORMATION}

Recording parameters

"Shot time" is the time an explosion 1s scheduled to be detonated. The SCR's are programed to turn on ten minutes prior to shot time to allow the SCR to stablize, perform and record diagnostic tests, and record calibration signals (F1gure 2.1). The time actually programed is called the instrument "turn on time". The instrument turn on time and a numerical code, $N$, 


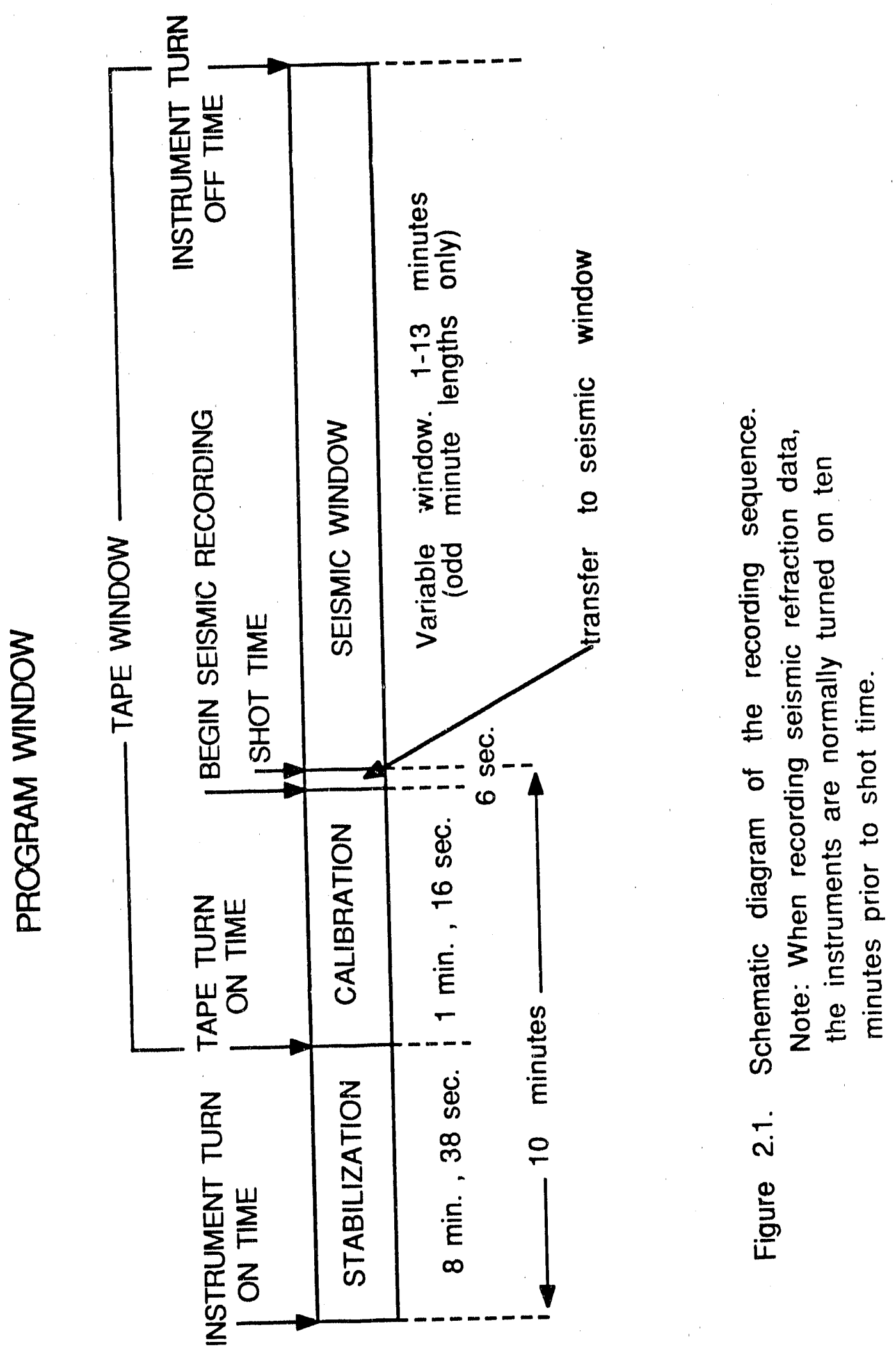


Indicating the recording duration will be refered to as "recording parameters" of a "program window". The function $2 \mathrm{~N}-1$ determines the number of minutes the SCR w1ll record selsmic data. Thls perlod 18 called the "selsmic window" (Table 2.1). The maximum recording duration code 187 , so the maximum selsmic window for one program window is 13 minutes. To extend the selsmic window beyond 13 minutes, two overlapping program windows are entered into the memory. For each non-overlapping window, an additlonal 1 minute and 16 seconds is used to record the dlagnostlc tests and calibration wave train. Additionally, the first 6 seconds of the selsmic. window are used for transfer to selsmic sensing. Therefore, the "tape wlndow" (the length of time the tape runs) is $2 \mathrm{~N}$ minutes plus 22 seconds and the instrument turn on time 1810 minutes prior to shot time.

Recording a selsmic window longer than 13 minutes requires two (or more) program windows. The instrument turn on t1me of the second program window should overlap the instrument turn off time of the first program window. For the second program window, the instrument will not run through a stabilization perlod and no diagnostic tests or calibration signals are performed or recorded (F1gure 2.2) so the instrument turn on time equals the "shot time" of figure 2.1. Normally, to extend the selsmic window beyond 13 minutes, the first program window contains a 13 minute selsmic window $(N=7)$, and the second program window contains an instrument turn on t1me 22 minures after the instrument turn on time in the first program window. In other words, the 1nstrument turn on time of the second program window 181 minute prior to the Instrument turn off time of the flrst program window (10 minute stabilization, calibration, and transfer time plus 13 minute selsmic window $=23$ minute program window). In this case, the selsmic window 1 s extended by $2 \mathrm{~N}-2$ minutes, where $\mathrm{N}$ is the recording duration code entered in the second program window and the instrument turn on time of the second program window is also the shot time (Figure 2.2). For example, to have a selsmic window 21 minutes long with seismic recording to start at 0600 , the recording parameters in the first program window should be: $N=7$, and 1nstrument turn on time $=0550$. The recording parameters in the second program window should be: $N=5$, and instrument turn on time $=0612$. The selsmic window may be extended further by adding a third program window which overlaps the second. Therefore, the recording duration $1 \mathrm{~s}$ limlted only by the amount of tape avallable ( 30 minutes).

There are ten program windows avallable in the SCR memory and all ten must be programed with recording parameters. Duplication of the recording parameters is not only permitted, it is recommended because it reduces the probability of an SCR fallure due to a memory malfunction. For example, to program two turn on times, the programer typlcally enters recurding parameters for the first turn on time in the first five program windows and recording parameters for the second turn on time in the last flve program windows. Examples of program windows are given in Table 2.2. 
Table 2.1

SESMIC WINDOW LENGTHS

\begin{tabular}{cc}
$N$ & SEISMIC WINDOW (m1n) \\
\hline 1 & 1 \\
2 & 3 \\
3 & 5 \\
4 & 7 \\
5 & 9 \\
6 & 11 \\
7 & 13
\end{tabular}

Table 2.2

PROGRAM WINDOW EXAMPLES

13 minute selsmic window beginning at *85 $0630 \mathrm{GMT}$

$(\star 85=$ Jultan day 185 , or 285$)$

5420450

9 minute selsmic window beginning at *420500 GMT

$(\star 42$ - Jullan day 142,242 , or 342$)$

7221850

7221912

29 minute seismic window beginning at *22 1900 GMT

3221924

$(\star 22=$ Jullan day 122,222 , or 322$)$ 


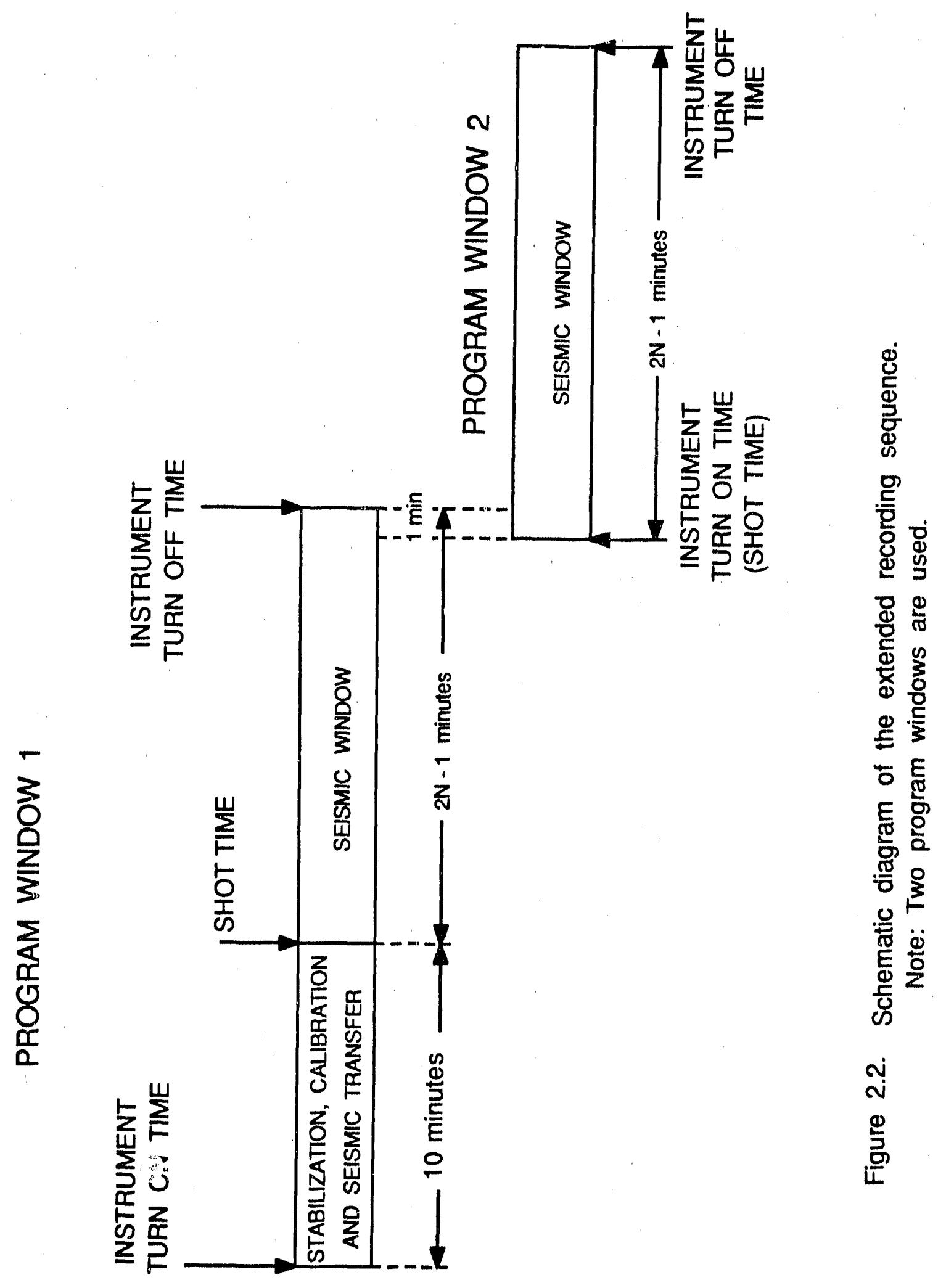




\section{Batterles}

The batterles for both the SCRs and HHTs can be recharged without removing them from the instrument. A speclally designed charging unit is bullt to charge 20 instruments and 1 HHT simultaneously. The charging unft consists of a power supply, a bank of 5-ohm reslstors, and 212 -wire cables with connectors. Two separate boxes house the resistor banks with ten test points each (the HHT connector has no test point). The power supply 1s connected to the resistor banks through detachable palrs of wires. The lnput to the power supply is $110 \mathrm{~V}$ AC current and the output is a DC current at one of two voltage levels - $14.9 \mathrm{~V}$ and $13.6 \mathrm{~V}$. The charging un1t's low voltage level 18 used to maintaln the batterfes during nonuse perlods and the high voltage level is used to quickly recharge the batterles after the SCR's have been used to record data. The batterles are fully charged when the charging un1t's output $1814.9 \mathrm{~V}$ and the batterles are drawing a current of approximately 100 $\mathrm{mA}$.

The condition of the batterles can be monitored at the test points on the resistor banks (F1gure 2.3). To determine how much current the batterles are drawing, measure the voltage drop across the resistor with a volt meter. The current being drawn by the batterles is the voltage drop divided by the resistance. Therefore, the batteries are fully charged when the voltage drop 1s approximately $0.5 \mathrm{~V}$.

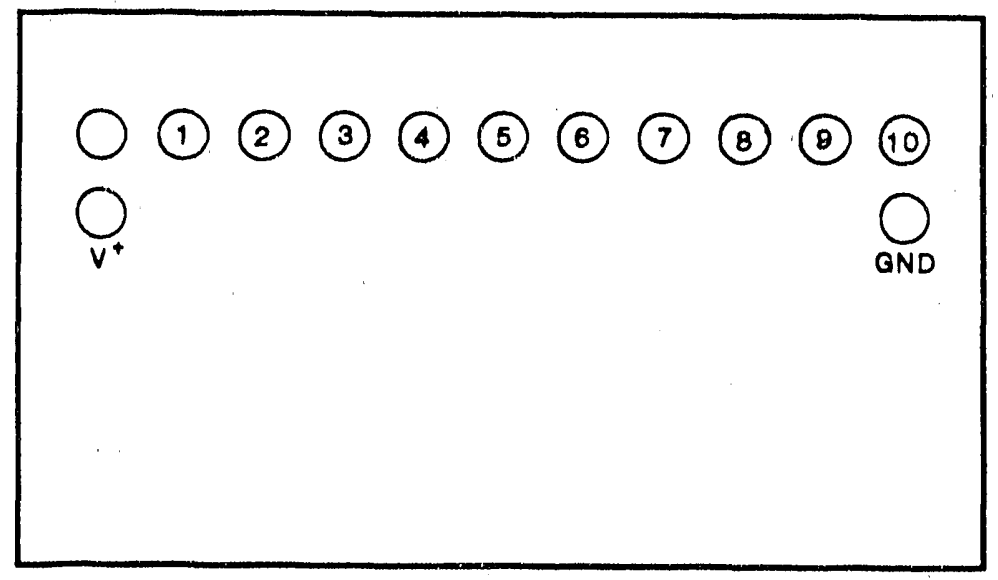

Figure 2.3. Schematic diagram of the resistor bank. 1-10 are the test points to measure the current being drawn by the SCR batteries. 


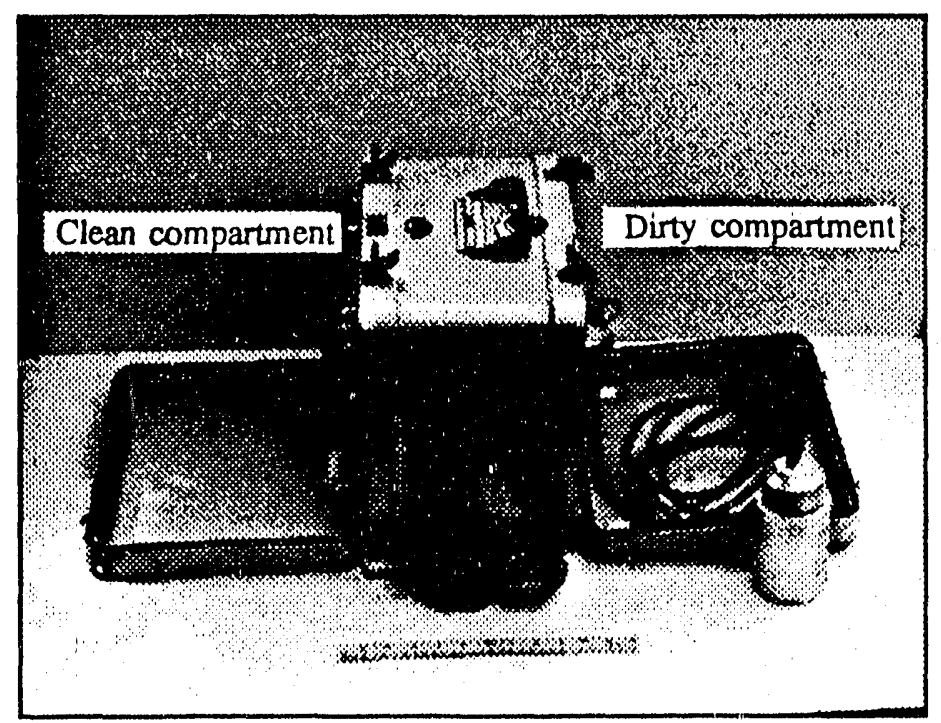

Figure 2.4 Seismic Cassette Recorder (SCR).

SCR

An SCR has two outer compartments that can be accessed by opening latched lids (Figure 2.4). The seismometer, a 48-pin connector, and the battery recharging connector are housed in the so called "dirty" compartment. This compartment is often contaminated by dirt from the seismometcr. When the seismometer is deployed or when the batteries are being recharged, this compartment remains unlatched. The latches should not be engaged when wires are exiting the lid, as this may damage them. The other outer compartment, called the "clean" compartment, houses the SCR user interface and data cassette recorder.

\section{Eield Notes}

Field notes are recorded on two data sheets -- the "recorder field data sheet" (alias "blue sheet") and the "deployment timing check list" (also called "white sheet"). The blue sheets are used to record attenuation settings and symptoms of instrument malfunctions. They are also used to associate a field location numbner with an SCR instrument serial number and a computer location number. The white sheets are used to record all timing information. Figure 2.5 is a blue sheet and figure 2.6 is a white sheet. 


\begin{tabular}{|c|c|c|c|c|c|}
\hline \multicolumn{6}{|c|}{ RECORDER FIELD DATA SHEET } \\
\hline \multicolumn{5}{|c|}{ Experiment: } & \multirow{4}{*}{$\begin{array}{l}\text { Shot No:: } \\
\text { Shot Date: } \\
\text { Jullan Day: }\end{array}$} \\
\hline \multirow{2}{*}{\multicolumn{5}{|c|}{$\begin{array}{l}\text { Deployment No.:_ Team No.: } \\
\text { Observers: }\end{array}$}} & \\
\hline & & & & & \\
\hline \multicolumn{2}{|c|}{ Attenuations: } & \multicolumn{3}{|c|}{$\operatorname{ch} 1 \ldots \operatorname{ch} 2$} & \\
\hline & \begin{tabular}{|l|} 
COMPUTER \\
LOCATION \\
NUMBER
\end{tabular} & \begin{tabular}{|c|} 
UNIT \\
NUMBER \\
\end{tabular} & $\begin{array}{c}\text { FIELD } \\
\text { LOCATION } \\
\text { NUMBER }\end{array}$ & $\begin{array}{c}\text { TAPE } \\
\text { GRADE }\end{array}$ & $\begin{array}{l}\text { NOTES } \\
\text { Inchde any attenuations which are ditherent than those } \\
\text { Wetted above }\end{array}$ \\
\hline 1 & & & & & \\
\hline 2 & & & & & \\
\hline 3 & & & & & \\
\hline 4 & & & & & \\
\hline 5 & & & & & \\
\hline 6 & & & & & \\
\hline 7 & & & & & \\
\hline 8 & & & & & \\
\hline 9 & & & & & \\
\hline 10 & & & & & \\
\hline 11 & & & & & \\
\hline 12 & & & & & \\
\hline 13 & & & & & \\
\hline 14 & & & & & \\
\hline 15 & & & & & \\
\hline 16 & & & & & \\
\hline 17 & & & & & \\
\hline 18 & & & & & \\
\hline 19 & & & & & \\
\hline 20 & & & & & \\
\hline
\end{tabular}

F1gure 2.5. Recorder fleld data sheet (blue sheet). 


\section{SCR PROJECT PROFILE}

\begin{tabular}{|c|c|c|c|c|c|c|c|c|c|c|c|c|}
\hline \multicolumn{8}{|c|}{$\begin{array}{l}\text { Deployment No: } \\
\text { Shot Date: Jullan Day: } \\
\text { Team No: } \\
\text { Observers: }\end{array}$} & \multicolumn{5}{|c|}{$\begin{array}{l}\text { HHT SET TIME } \\
\text { HHT CHECK TIME } \\
\text { HHT RESET TIME } \\
\text { HHT RECHECK TIME_ }\end{array}$} \\
\hline \multicolumn{13}{|c|}{ DEPLOYMENT \& TIMING CHECK LIST } \\
\hline \multicolumn{7}{|c|}{ PRE-DEPLOYMENT } & \multicolumn{6}{|c|}{ POST-DEPLOYMENT } \\
\hline \multirow{2}{*}{\multicolumn{2}{|c|}{$\begin{array}{l}U \\
N \\
1 \\
T\end{array}$}} & \multicolumn{3}{|c|}{ CLOCK SET } & \multirow{2}{*}{\begin{tabular}{|l|l}
$M$ & $A$ \\
$E$ & $T$ \\
$M$ & $T$
\end{tabular}} & \multirow{2}{*}{ 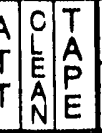 } & \multicolumn{3}{|c|}{ CLOCK CHECK } & \multirow{2}{*}{$\begin{array}{l}\text { DRIFT } \\
\text { (mSEC) }\end{array}$} & \multirow{2}{*}{ 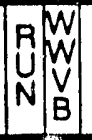 } & \multirow{2}{*}{$\begin{array}{l}\text { INSTRUMENT } \\
\text { PERFORMANCE }\end{array}$} \\
\hline & & DAY & $H$ & MIN & & & DAY & $\mathrm{HR}$ & MIN & & & \\
\hline F & & & & & & & & & & & & \\
\hline 2 & & & & & & & & & & & & \\
\hline 3 & & & & & & & & & & & & \\
\hline 4 & & & & & & & & & & & & \\
\hline 5 & & & & & & & & & & & & \\
\hline 6 & & & & & & & & & & & & \\
\hline 7 & & & & & & & & & & & & \\
\hline 8 & & & & & & & & & & & & \\
\hline 9 & & & & & & & & & & & & \\
\hline 10 & & & & & & & & & & & & \\
\hline 11 & & & & & & & & & & & & \\
\hline 12 & & & & & & & & & & & & \\
\hline 13 & & & & & & & & & & & & \\
\hline 14 & & & & & & & & & & & & \\
\hline 15 & & & & & & & & & & & & \\
\hline 16 & & & & & & & & & & & & \\
\hline 17 & & & & & & & & & & & & \\
\hline 18 & & & & & & & & & & & & \\
\hline 19 & & & & & & & & & & & & \\
\hline 20 & & & & & & & & & & & & \\
\hline
\end{tabular}

Figure 2.6. Deployment timing check 11st (white sheet). 
Past disasters and how to avold them

Over the years we have encountered varlous problems in SCR use. Some of these can be avolded and are discussed here.

In the SCR's tape deck, the tape from the cassette runs between a small 11ght and a photo sensor. The photo sensor turns off the tape recorder when 1t senses the 11ght. Therefore, the cassette tapes must be wound past the transparent leader before they are inrerted into the tape deck port. Normally we use only "no hole" cassette tapes, but "holed" tapes can be used if the tape is wound past the hole (whIch is an end-of-tape marker). Cassette tapes should be checked to determine whether there is a loading marker hole.

The most common reason an SCR w1ll not record data 16 that the cassette tape is not seated properly in the tape deck port. This 18 a persistant problem because the tapes are often unseated during transport to the fleld site. To eliminate this problem, observers remove the tape at the field location site, manually wind the tape until it 18 taught, and then place the tape back in the tape deck port. Then the tape 18 tapped gently to ensure proper seating.

Jarring during transport may cause loose objects stored in the outer compartments to fly around the compartment. Free flylng objects in the clean compartment sometimes hit the RUN/HOLD switch with oufficient momentum to turn off the 1nternal clock. For this reason nothing should be placed inside the clean compartment (1.e. empty cassette tape cases).

Lastly, connecting the SCRs to the battery recharger and falling to turn on the power supply can cause the batteries to drain if any of the SCRs has a current leak (short circult). Th1s problem is avolded by disconnecting the charglng cables when they are not in use. Short circuits can be detected by check1ng the voltage drops across the resistors.

\section{DESCRIPTION OF HHT AND SCR CONTROLS}

$\underline{\mathrm{HHT}}$

In order to simplify descriptions of the HHT, the front panel has been subdivided schematically into five subreglons - a display reg1on, an SCR remote control region, a memory reglon, a HHT clock control reglon, and a general functions region (F1gure 2.7). In the display reg1on, the left two ilquid crystal displays show elther the time of the HHT clock or the recording parameters of a single program window. The function displayed is determined by the display toggle switch ("25" on Figure 2.7). A memory entry is displayed when this display switch is in the " $M$ " position and the clock's time Is displayed when the display switch 18 in the " $C$ " position. When the time 1s displayed, the Jullan day appears in the left display and the hours, minutes, and seconds appear in the center display separated by colons. Each time-division is displayed in normal base 10 format (untts, tens, and 


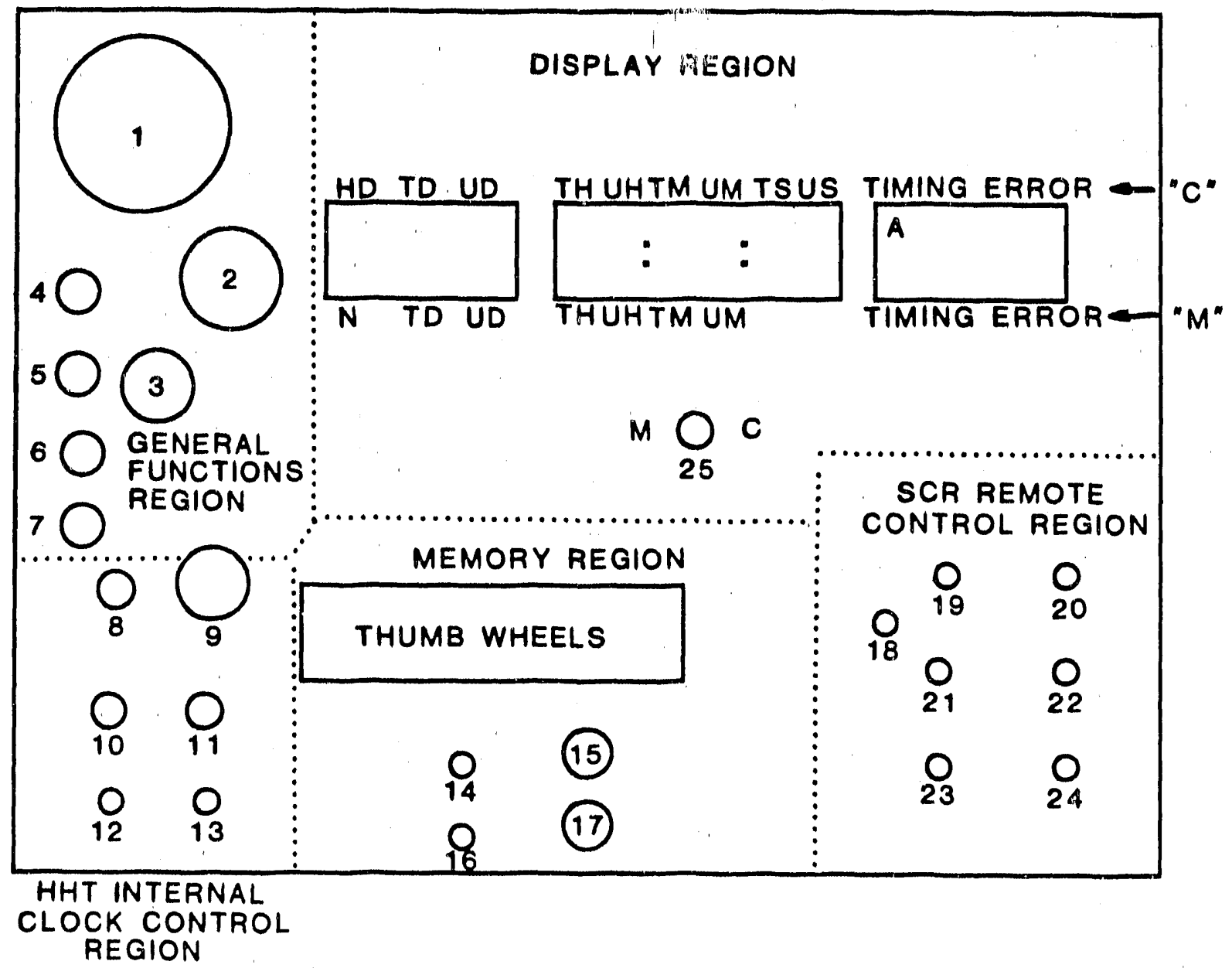

F1gure 2.7. HHT front panel.

GENERAI FUNCTIONS REGION

1. I/O connector

2. Battery recharger connector

3. Mon1tor sw1tch

4. Test point $A$

5. Test point B

6. Test point for time code

7. Test point ground

HHT INTERNAL CLOCK CONTROL REGION

8. Set button

9. Time division switch

(HD, TD, UD, TH, UH, TM, UM, TS)

10. RUN/HOLD switch

11. Reset button

12. ADV/RET switch (HHT clock)

13. Rate switch

\section{MEMORY REGION}

14. Select sw1tch (HHT/SCR)

15. Auto load button

16. Enter button

17. Reset button
SCR REMOTE CONTROL REGION

18. External callbration ow1tch (not used)

19. ADV/RET sw1tch

20. Rate sw1tch

21. Tape recorder play switch

22. Tape recorder direction switch

23. Tape recorder power switch

24. VCO power switch

\section{DISPLAY REGION}

$H D$ - hundreds of day (Julian)

TD - tens of day (Jullan)

UD - units of day (Jullan)

TH - tens of hours

UH - un1ts of hours

TM - tens of minutes

UM - units of minutes

TS - tens of Beconds

US - units of seconds

Timing erro: display

A. error bar

25. display switch

" $M$ " - memory

" $C$ " - time from the HHT clock 
hundreds). There are a total of nine digits used to display the time; elght of these can be set with the controls in the HHT internal clock control reglon (un1t seconds cannot be so controlled). When memory 18 displayed, the recording parameters of one program window are displayed. The numerical duration code 18 the most significant digit in the left display; the two less slgnificant digits are the two least signiflcant diglts of the Jullan day (1e. tens and units). The most significant Julian day digit (hundreds) is not used. The center display shows the hours and minutes separated by colons. Because the program window contains no seconds, this portion of the display is blank.

Whenever the 48-wire cable connecto the HHT to a master clock or an SCR, the time difference between the 1nternal clocks is shown on the right 11quid crystal display (timing-error display). The timing-error display shows a signed value in the range $+399.9 \mathrm{~ms}$. It 18 therefore possible to synchrontze the millisecond values from both clocks 80 that $a+0.1 \mathrm{~ms}$ value appears in the timing error display, but that the seconds, miñutes, hours, and days are not synchronized. For this reason, an error bar in the top left corner of the timing-error display flashes if any portion of the time is not synchronized (on some HHT"s the word "BAT" flashes). The error bar does not flash unt11 the timing error display shows less than a 1-ms error. For timlng errors less than 400 milliseconds, the Bign Indicates whether the remote clock (master clock or SCR clock) 1s faster or slower than the HHT clock. If the $81 \mathrm{gn}$ is negative the remote clock is behind the HHT clock otherwise the remote clock is ahead of the HHT clock. The SCR clock can be adjusted with the controls in the SCR remote control reglon. The master clocks cannot be controlled from this reglon. The legend of Figure $2.7118 \mathrm{sts}$ which switches control the remote functions.

The memory region contains the thumb wheels used to program the HHT memory and the controls for programming and verifylng the HHT and SCR memories. Controls for setting and adjusting the HHT clock are in the HHT internal clock control region. The general functions reglon contalns the I/O connector, the battery recharger connector, a monttor switch, and four test points. The monftor switch controls wh1ch SCR function is belng monitored through test points $A$ and $B$. Table 2.3 11sts the functions monltored at each position of the monitor switch.

\section{$\underline{\mathrm{SCR}}$}

The SCR's control interface, located in the clean outer compartment contalns attenuation controls, a clock display, clock controls, test polnts, and a tape deck port (Figure 2.8). 
Table 2.3

HHT MONITOR SWITCH POSITIONS

TEST POINT A

1 Amplifler from channel 1

2 Amplifier from channel 2

3 Amplifier from channel 3

4 not used

5 not used

6 not used

7 I Hz slgnal derived from SCR clock

8 WWVB D.C. voltage level (not currently used)

9 Voltage from SCR battery

10 Power supply card $+5 \mathrm{~V}$ regulated

11 Multiplexed signal from FSK (frequency shift key) board

12 Voltage from HHT battery

TEST POINT B

1 Modulated VCO signal from channel 1

2 Modulated VCO signal from channel 2

3 Modulated VCO signal from channel 3

4 not used

5 not used

6 not used

7. IRIG E signal dertved from SCR clock

8 WirVB t1me code output (not currently used)

9 Voltage recleved by SCR record board and tape deck

10 Power supply card $-5 \mathrm{~V}$ regulated

11 multiplexed signal to the record amplifier board

12 not used 


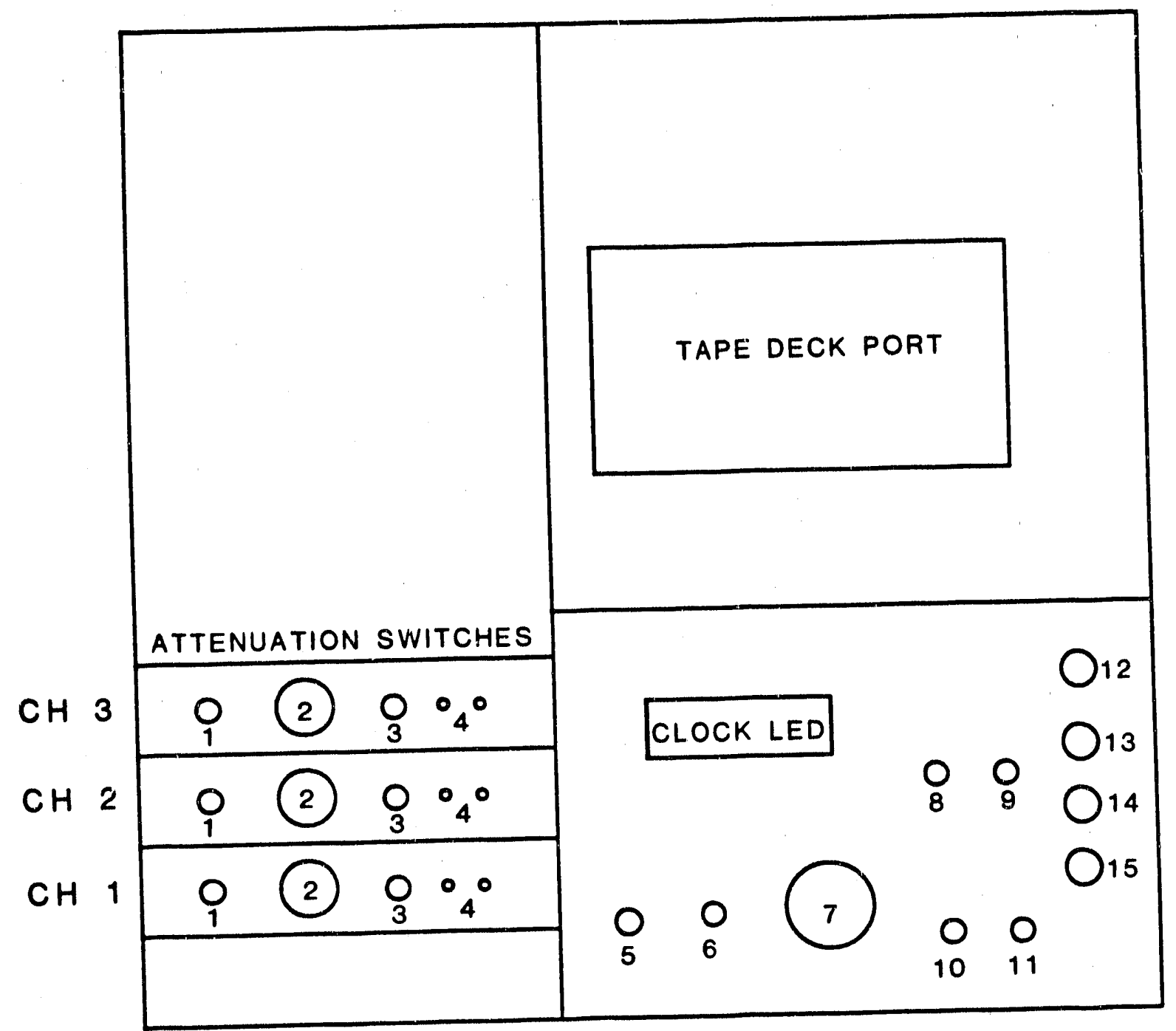

F1gure 2.8. SCR user interface.

1. Test point for amplifier

2. Varlable Attenuation switch

3. Attenuation toggle switch

4. Test points for FM carrier

5. Dispaly ON/OFF switch

6. Set button

7. Time division switch

8. RUN/HOLD switch
9. Reset button

10. ADV/RET switch

11. Rate switch

12. Test point for time code

13. Test point for $1 \mathrm{~Hz}$ signal

14. Input point for starting the clock automatically

15. Test point ground 


\section{PROGRAMMING PROCEDURES BEFORE DEPLOYMENT}

Before programming, obtain blue and white data sheets and a copy of the program times and attenuation settings for that deployment. Unwrap and label the cassette tapes with the SCR serlal number, the experiment name and year, and the deployment number, and wind the tape to the end of the clear leader. Then determine which master (reference) clock to use and program the HHT as described next.

Programming the HHT

To program the HHT, enter the recording parameters of all program windows into the HHT memory and synchronize the HHT internal clock with the master clock. After the HHT is programmed, record the GMT time of clock synchronization in the HHT section of the white data sheets. Then proceed to program each of the SCRs.

\section{Memory}

To enter recording parameters for the ten program windows into the HHT memory, position the memory select switch to "HHT" and push the memory reset button. For each set of recording parameters, set the thumb wheels with the recording duration code in the leftmost wheel followed by the turn on time (TD, UD, TH, UH, TM, UM); then press the memory-enter button. After ten such entries have been programed, the memory select switch should be set to the "REC" (1.e. SCR) position. The windows may be checked by positioning the display switch to the memory position ("M") and pushing the memory reset button. Repeatedly pressing the memory enter button will step through the sequence of programed windows. As the enter button is pushed, each window will be displayed and after the tenth wlndow, the sequence will repeat. Note that the memory select switch should normally be in the "REC" position so that accidental modification of the HHT memory does not occur.

\section{Synchronizing the internal clock}

Controls from the HHT internal clock control region of the user interface (F1gure 2.7) are used to set and synchronlze the HHT internal clock with a master clock. The synchronization process begins by visually comparing the display of the HHT with the display of the master clock. If the HHT and the master clock are not synchronlzed, the HHT 1nternal clock must be reset. There are two procedures to set the HHT clock - a manual procedure and an automatic procedure (both are described next).

If the HHT clock 18 more than 400 ms different from the master clock, reset the HHT clock manually or automatically. In both cases, to set the HHT Internal clock, move the run/hold switch to the hold position and press the reset button. Allowing enough time to set all elght time divislons, choose the time at which you intend to restart the clock. Normally 30-50 seconds ahead of the master clock (reference) time 18 sufficient, but during the first 
few attempts, the time chosen should be 2 minutes ahead of the master clock time. Set the HHT clock to this time by moving the switch which selects time divisions to the "TS" position and then pushing the set button repeatedly unt1l the desired number appears on the display in the tens of seconds position. Then move the time division switch to the "UM" position and agaln set the time by repeatedly pushing the set button unt1l the desired number appears in the undts of minutes position. In like manner, set all the other time divisions (note that a one appears in the UD position after the display has been reset). After the chosen time is set, restart the clock manually or automatically.

To restart the clock manually, prepare to move the run/hold switch to the run position then watch the display of the master clock. When the chosen time appears on the master clock display, immediately move the run/hold owitch to the run position. Confirm the clock is set correctly by visually comparing the time display of the HHT and the master clock. If the displays differ repeat this section. Finally, synchronize the HHT clock as described later.

To restart the clock automatically, set the "start minute" thumb wheel on the master clock to the minute chosen to start the HHT clock. Move the run/hold swltch to the center position and attach the $48-w 1$ re cable to the I/O connectors in the HHT and the master clock. The HHT clock will start at the chosen minute. Then move the run/hold switch to the run position and correct any remalning time difference as described next.

If, as 18 most often the case, the HHT clock does not need to be set, connect one side of the 48-wire cable to the I/O connector on the HHT and connect the other side of the cable to the I/O connector on the master clock. The time difference between the two clocks may now be read from the timing error display on the HHT. If the timing error displayed is more than 10 milliseconds, hold the rate switch in the $100 \mathrm{~ms} / \mathrm{s}$ position and move the ADV/RET switch to advance or retard the HHT clock. At this speed the clock changes quickly, so movements of the ADV/RET switch should be brief. When the timing error approaches $10 \mathrm{milliseconds,} \mathrm{the} \mathrm{rate} \mathrm{switch} \mathrm{should} \mathrm{be} \mathrm{moved} \mathrm{to}$ the $1 \mathrm{~ms} / \mathrm{s}$ position and the ADV/RET switch held in position until the error approaches $t 1 \mathrm{~ms}$. Thereafter movements of the ADV/RET switch should be brief unt1l a timing error of $\pm 0.1 \mathrm{~ms}$ is displayed. If the error bar starts flashing when the timing error falls below $1 \mathrm{~ms}$ and does not stop flashing within 20 seconds, compare the displays of the HHT and the master clock and then resynchronize the HHT (the error most often is one second). After the HHT has been programmed, start programing the SCRs.

Programming the SCR

To program an SCR, attach the 48-wire cable to the I/O connector on the HHT Interface pannel and to the I/O connector in the "dirty" compartment of the SCR. Load the SCR memory and Bynchronize the SCR Internal clock w1th the HHT 1nternal clock as described below. Lastly, set the attenuation switches and place the cassette tapes in the tape deck port. 


\section{Memory}

To load the SCR memory, position the HHT memory select switch to "REC", press the memory reset button and then push the "auto load" button. This proceedure enters all ten program windows 1nto the SCR's memory. In order to verify the contents of the SCR's memory, move the display switch to the " $M$ " position and with the memory select switch st111 on "REC" press the reset button. Now toggle the memory select switch. Each t1me this switch 1s moved to the "HHT" position, a new SCR program window w1ll be displayed. After the tenth window 18 displayed, the first window w1ll appear again. Continued toggling will repeat the cycle.

\section{Synchronizing the SCR 1nternal clock}

To synchronize the SCR internal clock with the HHT's internal clock, move the HHT display switch to the " $\mathrm{C}$ " position and visually compare the HHT display with the SCR display. If the two clocks do not agree, reset the SCR's internal clock using the controls in the clean compartment of the SCR. Proceed as described above for manually resetting the HHT's internal clock but In this case, reset the SCR clock and not the HHT clock. When the two displays agree, use the clock adjustment switches in the "SCR remote control region" of the HHT to correct any fractional second SCR clock error. If the SCR clock error 18 greater than $10 \mathrm{~ms}$ hold the rate switch in the $100 \mathrm{~ms} / \mathrm{s}$ position and use the ADV/RET switch to reduce the time difference to within $10 \mathrm{~ms}$. For smajler adjustments, position the rate switch to $1 \mathrm{~ms} / \mathrm{s}$ and push the ADV/RET switch to advance or retard the SCR clock. If the error bar starts flashing when the timing error falls below 1 ms, compare the displays of the HHT and the SCR. If the displays are the same, let the SCR stabilize. Ten seconds after the next minute mark the error bar should turn off. If the displays differ (commonly in the unit seconds time division), resynchronize the SCR clock. After the SCR clock has been synchronized, record the GMT t1me on the white sheet.

The adjustment switches in the "clean" compartment of the SCR may be used to correct the timing error in place of the controls in the HHT remote control region. Some people prefer this method because it precludes accidently changing the HHT's clock to match the clock in the SCR:

\section{Attenuations and cassette tape}

To set the attenuation, open the clean compartment of the SCR. There are two attenuation switches per data channel and the sum of their values is the total attenuation value for that channel. For example, if the variable switch is set to 48 and the toggle switch is set to 20 , then the total attenuation is $68 \mathrm{db}$ for that channel. From top to bottom, the channels are 3,2 , and 1 (Figure 2.8). Set the attenuation switches to the settings designated for this unit. Normally, the lowest attenuation (h1ghest galn) is channel 2 and the highest attenuation (lowest gain) is on channel 3.

Place a cassette tape in the tape deck port so that the unused tape 18 
spooled on the left opindle. Tap the tape gently to ensure proper seating. Each tape should be labeled with the SCR number, the experiment name and year, and the deployment number. Finally, record the attenuation settings on the blue sheet. Then proceed to the next SCR.

After the last SCR has been programmed, compare the HHT clock to the master clock and record on the white sheet the drift of the HHT clock during programming. Then connect the battery charger and recharge the SCR batterles.

Charging the SCR Batteries

The batterles should be recharged prior to deployment of the SCRs. To recharge the batterles, connect each of the SCRs and the HHT to the 2-w1re cables and check the connection between the resistor bank and the power supply. Then turn on the power supply and position the voltage level output to $14.9 \mathrm{~V}$. Last, check the charg1ng rate of each SCR by measuring the voltage drop across each resistor. If the SCR's have not been on high charge, they will draw current which will result in a voltage drop greater than $0.9 \mathrm{~V}$. A voltage drop close to zero usually Implies a bad connection and should be reported immediately to malntenance personnel. A fully charged SCR gives a voltage drop of $0.20 \mathrm{~V}$ to $0.50 \mathrm{~V}$.

\section{PROCEDURE AFTER RETRIEVAL OF THE SCR'S}

After the SCR's have been retrleved their internal clock drifts must be recorded on the white sheets, the batteries recharged, and malfunctioning instruments 1dentifled froin playbacks of the diagnostic tests recorded on each tape (playback procedures are not discussed here).

Recording drift times

To record the drift times after the SCRs have been retrleved, synchronize the HHT Internal clock with the master clock as described above. Attach the 48-wire cable to each SCR and record both the GMI time and the drift on the white data sheets. After all the SCR drifts have been recorded, compare the HHT to the master clock and record the drift of the HHT clock while the SCR drifts were measured.

\section{MISCELLANEOUS HHT FEATURES}

In addition to programming, the HHT provides a means of monitoring the SCR 1nternal electronics at various stages (Table 2.3) and provides external control of the tape deck. To control the SCR tape recorder, first, turn on the SCR "VCO" power then the SCR "REC" power. NOw, the tape recorder can be controlled from the SCR remote control region of the HHT. If the cassette tape 18 locked in the tape deck port, turning on the "VCO" power switch and then the "REC" power switch will cause the locking bar to retract. 


\section{ACKNOWLEDGMENTS}

The author would 11ke to express her appreclation to John VanShaack, Gray Jensen, Will Kohler, Bob McClearn, and to Ron Kaderabek for the1r assistance and detained explainations of the recording unit and the digltizing unit. Also, appreclated are comments from Tom Brocher, Bob Colburn, Ph11 Dawson, J1m Luetgert, Rob Luz1tano, J1ll McCarthy, and Allan Walter and revlews by John VanShaack and John Evans. 
Dawson, P.B., Stauber, D.A., 1986, Data report for a three-dimensional h1gh-resolution P-velocity structure 1nvestigation of the Summit Caldera of Newberry Volcano, Oregon, using selsmic tomography: U.S. Geological Survey Open-f1le Report 86-352.

Dratler, J., 1980, Theoret1cal transfer functlons for stations in the Central Californla selsmographic network: U.S. Geological Survey Open-file Report 80-376.

Eaton, J.P., 1975, Harmonlc magniflcat1on of the complete telemetered selsmic system, from selsmometer to fllm viewer screen: U.S. Geological Survey Open-f1le Report.

Eaton, J.P., 1977, Freqeuncy response of the USGS short per1od telemetered selsmic system and 1ts sultabllity for network studfes of local earthquakes: U.S. Geologlcal Survey Open-flle Report 77-844.

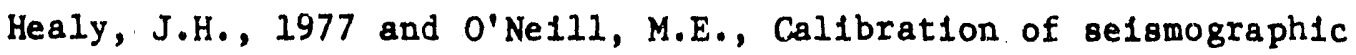
systems: USGS stations in the Central California network: U.S. Geological Survey Open-f1le Report 77-736.

Healy, J.H., Mooney, W.D., Blank, H.R., Gettings, M.E., Kohler, W.M., Lamson, R.J., Leone, L.E., 1982, Saud1 Arablan selsmlc deep-refraction proflle: flnal report: U.S. Geologlcal Survey Open-F1le Report USGS-OF-02-37, 141 pp.

Stewart, S.W., and O'Ne111, M.E., 1980, Calculat1on of the frequency response of the USGS telemetered short-period selsmic system: U.S. Geological Survey Open-f1le Report 80-143. 
Append1x A: A decoded example of the IRIG-E tIme code. 


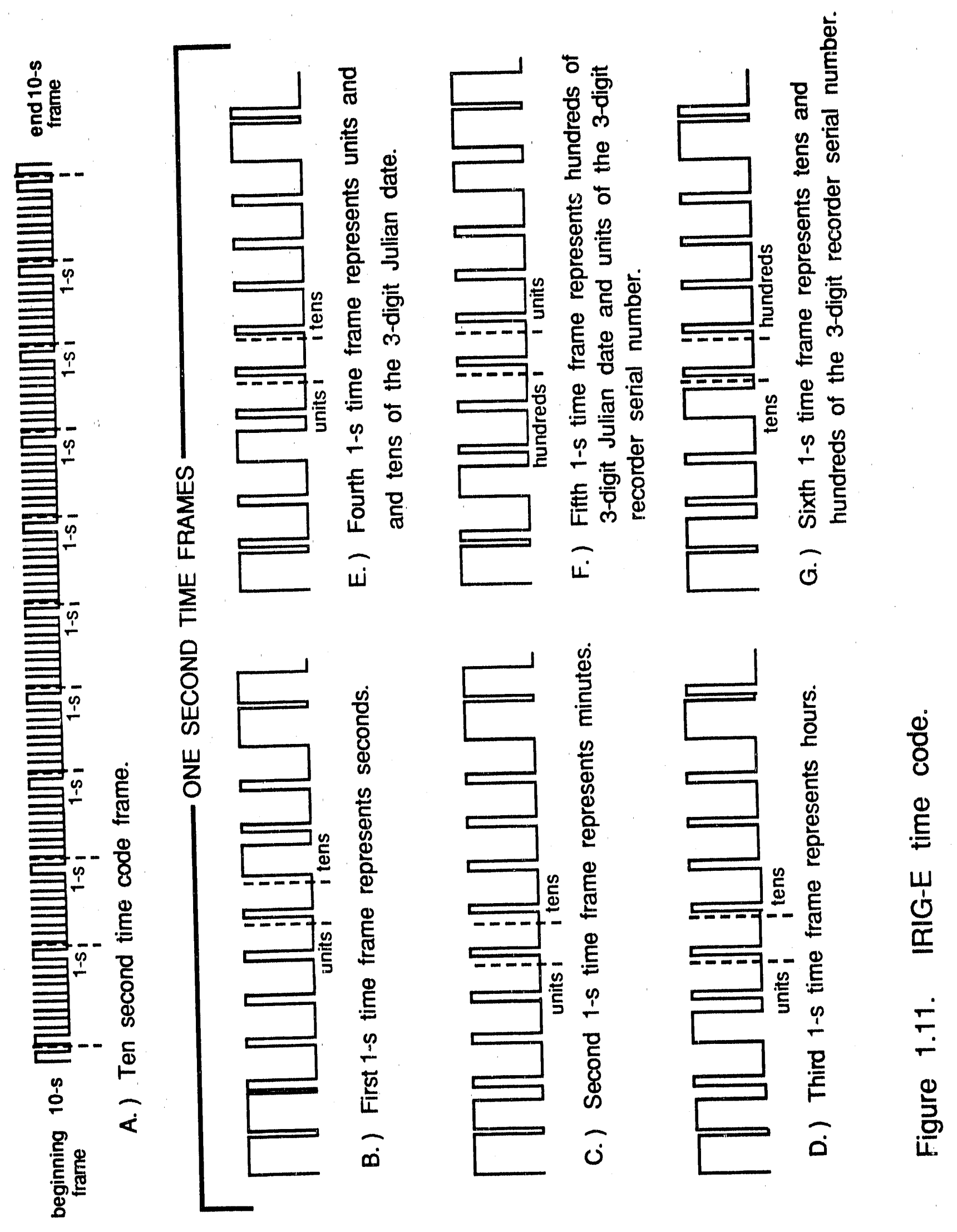



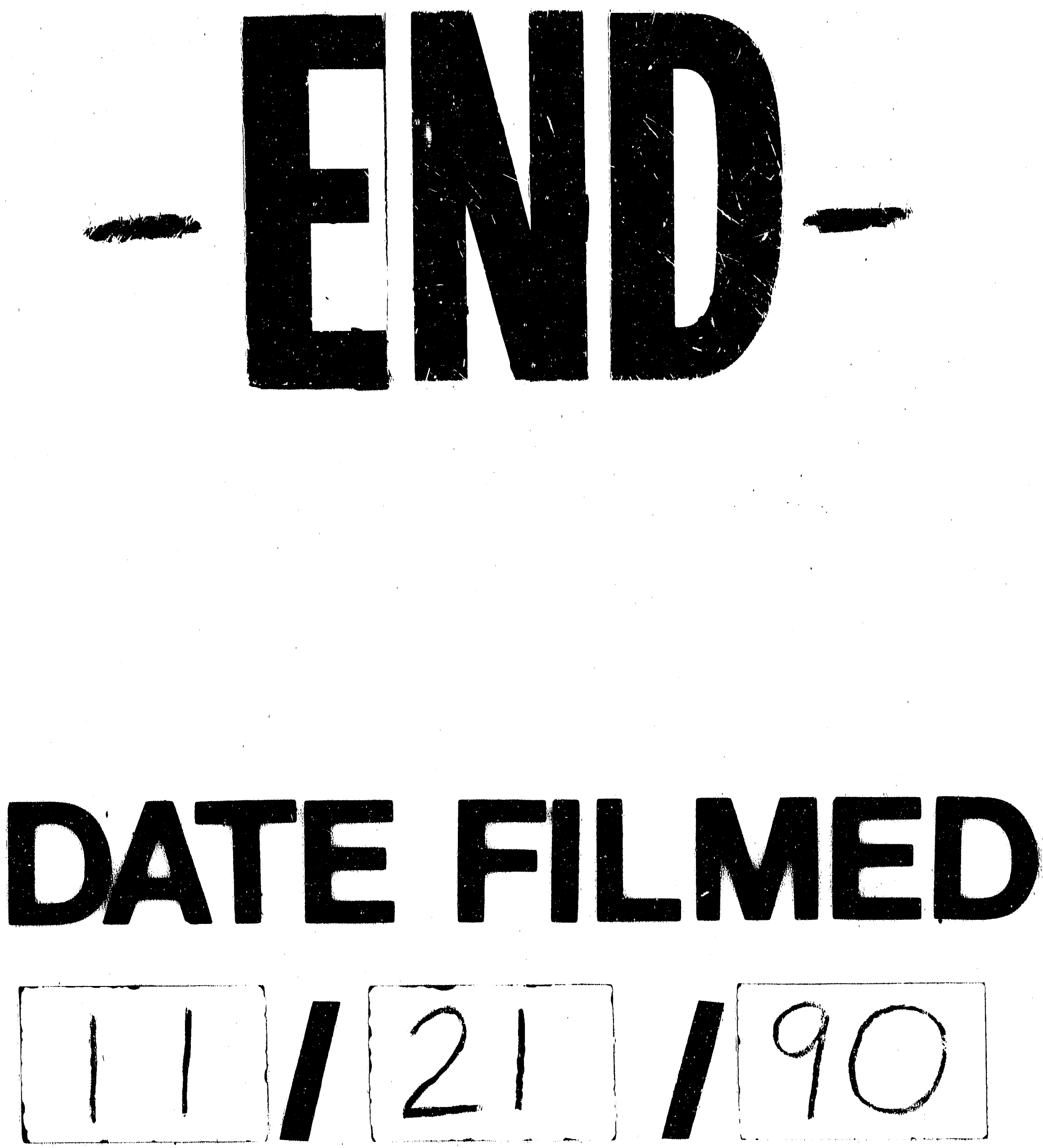


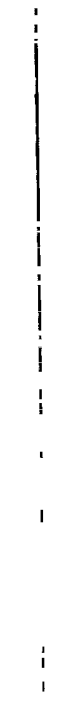

